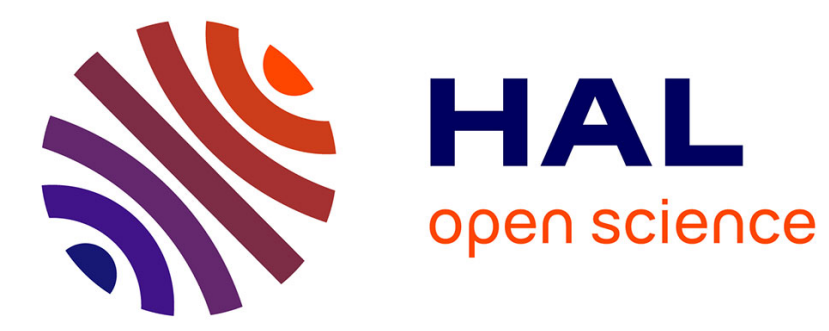

\title{
Modelling the reactions of cellulose, hemicellulose and lignin submitted to hydrothermal treatment
}

\author{
A.M. M Borrero-López, E. Masson, A. Celzard, V. Fierro
}

\section{To cite this version:}

A.M. M Borrero-López, E. Masson, A. Celzard, V. Fierro. Modelling the reactions of cellulose, hemicellulose and lignin submitted to hydrothermal treatment. Industrial Crops and Products, 2018, 124, pp.919-930. 10.1016/j.indcrop.2018.08.045 . hal-03207572

\section{HAL Id: hal-03207572 \\ https://hal.univ-lorraine.fr/hal-03207572}

Submitted on 30 Apr 2021

HAL is a multi-disciplinary open access archive for the deposit and dissemination of scientific research documents, whether they are published or not. The documents may come from teaching and research institutions in France or abroad, or from public or private research centers.
L'archive ouverte pluridisciplinaire HAL, est destinée au dépôt et à la diffusion de documents scientifiques de niveau recherche, publiés ou non, émanant des établissements d'enseignement et de recherche français ou étrangers, des laboratoires publics ou privés. 
$7 \quad 1$ Université de Lorraine, CNRS, IJL, F-88000 Epinal, France

(6)

(

\section{Abstract} compounds from lignin HTC was also considered.

\section{Modelling the reactions of cellulose,} hemicellulose and lignin submitted to hydrothermal treatment

A.M. Borrero-López ${ }^{1}$, E. Masson ${ }^{2}$, A. Celzard ${ }^{1}$, V. Fierro ${ }^{1 *}$

2 CRITT Bois, 27 rue Philippe Seguin, BP 91067, 88051 Epinal Cedex 9, France

The main compounds of plant biomass, i.e., cellulose, lignin and hemicellulose, were submitted to hydrothermal carbonisation (HTC) in ranges of temperature and time of $140-240^{\circ} \mathrm{C}$ and $0.5-24 \mathrm{~h}$, respectively. Those parameters were combined into a single one, the severity factor, and its effect on hydrochar yield on the one hand, and on $\mathrm{pH}$, yield and composition of the liquid fraction on the other hand, was investigated in depth. The production of furanic and phenolic compounds was correlated with both severity and $\mathrm{pH}$. The kinetics of furfural (FU) and 5-hydroxymethylfurfural (5-HMF) production and consumption were also investigated and modelled, and the results were compared to those reported in the literature. The production of nine phenolic

\footnotetext{
*Corresponding author. Tel: + 333727496 77. Fax: + 333727496 38. E-mail address : Vanessa.Fierro@univ-lorraine.fr (V. Fierro)
} 


\section{Introduction}

Hydrothermal carbonisation (HTC), whose history dates from the early 1900's (Bergius, 1915), is a very simple process by which a bioresource is submitted to mild temperatures $\left(130-250^{\circ} \mathrm{C}\right)$ in a pressurised liquid medium (generally pure water) using a closed reactor, i.e., an autoclave. In the latter, the pressure is self-generated and allows obtaining both solid and liquid products (Borrero-López et al. 2017).

HTC is cost-effective as it does not require chemicals and avoids costs related to materials drying, and it perfectly allows biomass conversion into high added-value organic compounds through hydrolysis and subsequent dehydration and fragmentation (Braghiroli et al., 2015). Cellulose, hemicellulose and lignin are the main macromolecular compounds of wood and plant biomass in general, and the former two macromolecules are well-known precursors of furfural (FU) and 5-hydroxymethylfurfural (5-HMF), respectively, when submitted to HTC. HTC of lignin can also provide some valuable compounds like vanillin, used for cosmetics and flavouring, or syringaldehyde, used as ingredient for food and flavour (Onwudili, 2015, Zhou, 2014), amongst others.

However, a solid carbonaceous residue, called hydrochar, is also obtained in the same process, having many interesting features such as porosity and functional groups like hydroxyls, carbonyls, etc (Chen et al., 2017). Hydrochars are interesting by-products as they present higher heating values (Basso et al., 2015) than their corresponding biomass precursors, and have been proposed for soil amendment (Steinbeiss et al., 2009), for $\mathrm{CO}_{2}$ capture (Jatzwauck and Schumpe, 2015) or as precursors of carbon materials (Borrero-López et al., 2017, Braghiroli et al., 2012, 2015b).

Extensive work has been carried out on HTC of many kinds of bioressources, like wheat straw (Reza et al., 2015), plant biomass wastes (Fang et al., 2015), loblolly pine (Lynam et al., 2011), soft rush (Jatzwauck and Schumpe, 2015) as well as on each 
individual major compound of such biomass (Lu et al., 2013, Gao et al., 2012,

47 Pińkowska et al., 2011, Wang et al., 2015). However, only a few works combined the studies of cellulose, hemicellulose and lignin. For instance, Kang et al. (2012) previously focused on HTC of the latter compounds, amongst others, but only a rather narrow temperature range was investigated and no detailed studies of the liquid products was performed. As far as we know, no research related to the liquid and solid fractions obtained from cellulose, hemicellulose and lignin submitted together to HTC has been published.

In the recent past, the kinetics of FU production / decomposition competitive reactions (Marcotullio et al., 2009) were thoroughly studied for several biomasses or biomass-derived molecules such as wheat straw (Yemiş and Mazza, 2012) and xylose or on decomposition reactions separately (Liu et al., 2014, Danon et al., 2014, Kim et al., 2011). Simple consecutive reaction models as well as models taking into account side reactions have been developed (Jing and Lü, 2007, Liu et al., 2014) and are in et al., 2014, Yang et al., 2012, Chen et al., 2012). An intermediate between xylose and furfural has also been proposed for explaining the kinetics of FU production (Marcotullio, 2011 and Chen et al., 2015). production whereas Girisuta et al. (2006) studied its decomposition to levulinic acid, but again there was not too much work related with these two competitive processes in the same study (Jing and Lü, 2008, Shen and Wyman, 2012). The case of 5-HMF is more complex than that of FU, because some degradation products are known to decompose afterwards, such as levulinic acid. 
The main purpose of the present work was to assess the effect of HTC conditions on lignin, cellulose and hemicellulose in a broad range of temperatures $\left(140-240^{\circ} \mathrm{C}\right)$ and time (0.5-24 hours), by studying the production of FU, 5-HMF and up to nine aromatic compounds as a function of HTC severity, and to apply simple models for describing the observed kinetics. Relationships between the latter and $\mathrm{pH}$, and yields of resultant liquid and solids, were also looked for.

\section{Material and Methods}

\subsection{Raw material}

Cellulose was Type 102 VIVAPUR (high-purity) microcrystalline cellulose provided by JRS Pharma (Rosenberg, Germany). Hemicellulose was high-purity xylan extracted from beech wood and supplied from Roth (Karlsruhe, Germany). Lignin used was lignin powder Lignine PROTOBIND 1075 (Asian Lignin Manufacturing India Private Limited), which is soda lignin. All compounds used for identification and quantification of phenolic and furanic compounds by HPLC were analytical grade and purchased from Sigma-Aldrich (Steinheim, Germany).

\subsection{Hydrothermal carbonisation (HTC)}

HTC experiments were performed in $100 \mathrm{~mL}$ Teflon®-lined autoclaves. The liquid to solid (L/S) weight ratio was 8 (16 g/ $2 \mathrm{~g}$ ) where L stands for liquid (i.e., pure water) and $\mathrm{S}$ for the considered biomass compound (BC) on dry basis. $\mathrm{BC}$ and distilled water were thus weighed and introduced in a glass insert so as to protect the PTFE liner of the autoclave from any contamination. Autoclaves were next hermetically closed and placed in a ventilated oven preheated at the desired temperature $(160,170,180,200$, 220 or $240^{\circ} \mathrm{C}$ ) for the required reaction time (from 0.5 to 24 hours). Afterwards, the 
autoclaves were removed from the oven and let to cool down to room temperature for several hours before opening.

Since both time $(t)$ and temperature $(T)$ produce changes in the results of the HTC process, their effect was investigated through the severity factor $\left(\log R_{0}\right)$ which was introduced to combine these two parameters into a single one (Overend and Chornet, 1987). Indeed, $\log R_{0}$ takes into account the different significances of these two parameters through an exponential factor for the temperature, and through a proportional factor for time. It reads:

$$
\log R_{0}=\log \left[t \cdot \exp \left(\frac{T-100}{\omega}\right)\right]
$$

where $t$ is the residence time (min), $T$ the working temperature $\left({ }^{\circ} \mathrm{C}\right)$ and $\omega$ is an HTC parameter. The initial value for lignocellulosic materials that was suggested for $\omega$ was 14.75 , since it corresponds to the activation energy of a first-order hydrolytic process (Xu et al., 2011). As it remains an empirical parameter, $\omega$ was sometimes changed when using other bioresources and different temperature ranges, as did Ko et al. (2015) for glucose by using the value 4.6.

\subsection{Liquid/solid separation and analysis}

After HTC, liquid and solid products obtained together in the autoclave were separated by vacuum filtration. The amount of liquid was weighed immediately after filtration, whereas solids were placed in a vacuum oven for 6 hours at $60^{\circ} \mathrm{C}$ for complete drying and subsequent weighing.

Qualitative identification of the main volatile compounds in the liquid phase was carried out by gas chromatography coupled with mass spectrometry (Clarus 500 GC/MS). Regarding quantitative analyses, furanic and phenolic compounds were 
119 determined using an Ultimate 3000 high-performance liquid chromatograph equipped 120 with auto-sampler, diode array and fluorescence detectors, and columns described 121 below.

A Hypersyl Green PAH column was used for FU, 5-HMF and 5-MF quantification. Four UV absorption wavelengths were used, i.e., 220, 276, 284 and $291 \mathrm{~nm}$. Doing so, fluorescence and emission occurring at wavelengths of $360 \mathrm{~nm}$ and $443 \mathrm{~nm}$, respectively, could be avoided. Water and acetonitrile were used as mobile phases and the acetonitrile/water ratio was changed from $5 / 95$ to $100 / 0$ during the $35 \mathrm{~min}$ of the total analysis time as follows: in the first $1.5 \mathrm{~min}$, the 5/95 ratio was maintained; from 1.5 to $15 \mathrm{~min}$, acetonitrile increased linearly up to a $50 / 50$ ratio; from 15 to $20 \mathrm{~min}$, the acetonitrile again increased up to 100/0 and this ratio was maintained for 5 min more.

130 From 25 to $30 \mathrm{~min}$, acetonitrile decreased until the initial ratio, i.e., 5/95, and it was maintained 5 min until the end of the analysis.

Phenolic compounds were quantified with a Pinnacle DB BiPh $5 \mu$ m column, and UV absorption wavelengths of 195, 201, 231 and $300 \mathrm{~nm}$ were used. Mobile phases were water and acetonitrile too. The program started with an acetonitrile/water ratio of 10/90 during the first $3 \mathrm{~min}$. Later, the acetonitrile content increased up to $15 / 85$ at $\min 5$, and remained constant until min 13 . From 13 to $15 \mathrm{~min}$, acetonitrile increased up to the ratio 20/80 and was kept constant 13 min more. From 28 to $33 \mathrm{~min}$, the acetonitrile concentration increased up to the ratio 100/0, which was kept for 5 min more. From 38 to 43 min, acetonitrile concentration decreased to 90/10 ratio, and remained constant for

$1407 \mathrm{~min}$ more, until the end of the experiment at $50 \mathrm{~min}$. Again, all the aforementioned changes of the acetonitrile/water ratio were linear. following equation: 
145 where $[X]$ is the concentration $\left(\mathrm{g} \mathrm{mL}^{-1}\right)$ of each soluble organic compound within the

146 volume $V$ of liquid (mL) obtained after $\mathrm{HTC}$, and $W_{B C}$ is the mass $(\mathrm{g})$ of the biomass 147 component studied on dry basis.

148 The hydrochar yield, $Y_{H C}$, was determined from Eq. (3):

149

$$
Y_{H C}(\%)=\frac{W_{H C}}{W_{B C}} \times 100
$$

where $W_{H C}$ is the mass of dry hydrochar after HTC.

The liquid yield from HTC, $L Y_{H C}$, was calculated as follows:

$$
L Y_{H C}(\%)=\frac{L W_{H C}}{L W_{0}} \times 100
$$

where $L W_{H C}$ is the amount of liquid weighed after filtration, and $L W_{0}$ is the initial amount of liquid added in the autoclave.

\subsection{Kinetics}

The fits to experimental kinetic data was carried out with OriginPro 8.5.1 software by minimising $\chi^{2}$ through the Levenberg-Marquart algorithm. Simple models considering successive decomposition reactions either without or with side reactions, herein called A and B models, respectively (Perez and Fraga 2014, Marcotullio, 2011) were applied to the data, and allowed deriving kinetic parameters for each temperature and for each raw material. The as-obtained kinetic parameters were investigated as a function of temperature using Arrhenius equation, Eq. (5). Both activation energy $\left(E_{a}\right)$ and pre-exponential factor $\left(k_{0}\right)$ were obtained from the slope and intercept of the corresponding fitting, respectively.

$$
k=k_{0} e^{-\frac{E_{a}}{R T}}
$$




\subsection{Changes of $\mathbf{p H}$}

HTC of cellulose, lignin and hemicellulose produced some changes in the $\mathrm{pH}$ of the water in which the process was carried out. Different behaviours were observed, depending on the raw material and on the conditions of the experiments.

Thus, for hemicellulose, the $\mathrm{pH}$ first decreased with time (Fig. 1a) likely due to the production of significant amounts of small acidic molecules. Then, the $\mathrm{pH}$ either remained low or increased afterwards at higher reaction time, depending on the temperature. Such behaviour is more clearly seen when the $\mathrm{pH}$ is plotted versus severity (Fig. 1b), i.e., once time and temperature have been combined into one single parameter. The $\mathrm{pH}$ thus increased above a severity of 5, probably because more severe conditions produced secondary reactions which led to the decomposition of low molecular-weight acids as already observed elsewhere (Shen et al., 2012). It might be $a$ priori thought that $\mathrm{FU}$ and 5-HMF account for the decrease of $\mathrm{pH}$ of the solutions recovered after HTC of hemicellulose and cellulose, respectively, since they are generally found at the highest concentrations when the $\mathrm{pH}$ decreased the most. However, as furfural is not acidic and 5-HMF possess a $p K_{a}$ of 12.82 , the conditions of their formation at highest concentration may be responsible of the production of other species such as acetic acid, furoic acid, formic acid, lactic acid, propionic acid, butyric acid and others (Zeitsch, 2000, Reza et al., 2014), which really account for the low pH observed.

Roughly similar trends were found when cellulose was submitted to HTC (Fig. 1c), i.e., the $\mathrm{pH}$ was the highest at the beginning of the process then decreased and stabilised or slightly increased after $6-12 \mathrm{~h}$, depending on the temperature. The $\mathrm{pH}$ dropped more at higher temperature, but also increased more after the minimum. This trend can be 
192 again explained in terms of increased degradation of soluble products when the severity 193 increased (Fig. 1d), and the apparently constant $\mathrm{pH}$ at lower HTC temperature is likely 194 due to reaction times that were too low for causing any significant change of $\mathrm{pH}$.

195 As for lignin submitted to HTC, the $\mathrm{pH}$ of the liquid phase increased with severity 196 (Fig. 1f). This is due to the fact that lignin degradation mainly produces phenolic (i.e., 197 basic) compounds, and not acids. The red solid lines in Fig. 1b, 1d and 1f are fits of a 198 second-order polynomial, Eq. (6), to the experimental data, where $p_{1}, p_{2}$ and $p_{3}$ are 199 adjustable parameters. The values of the latter are given in Table 1. 
(a)

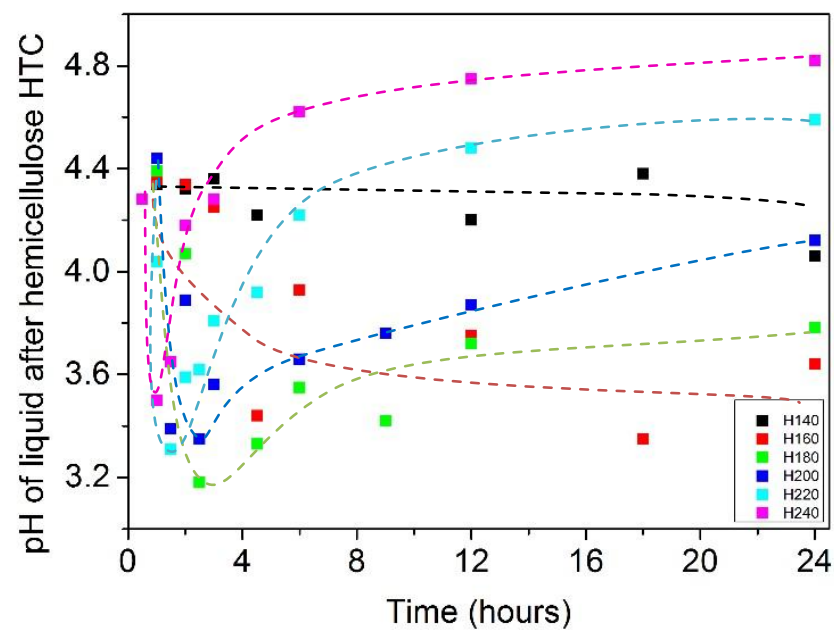

(c)

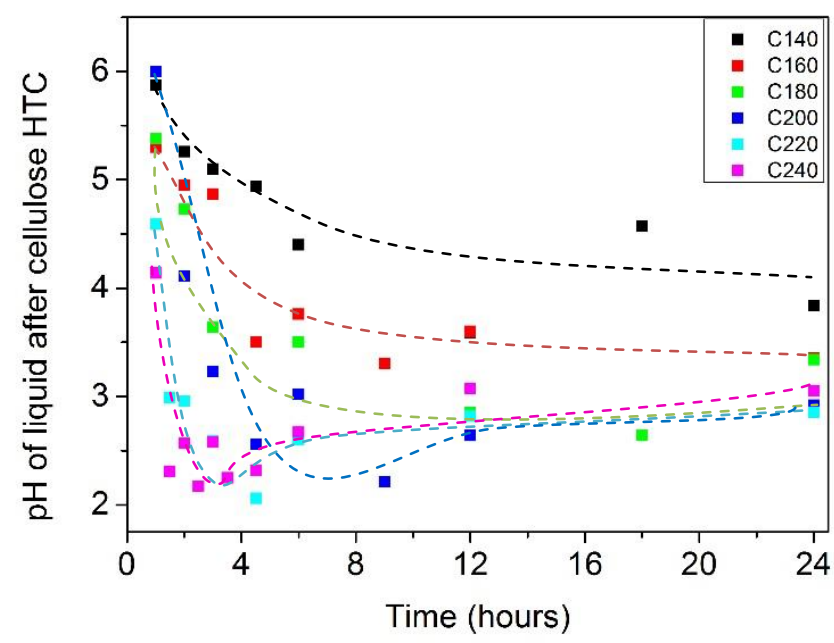

(e)

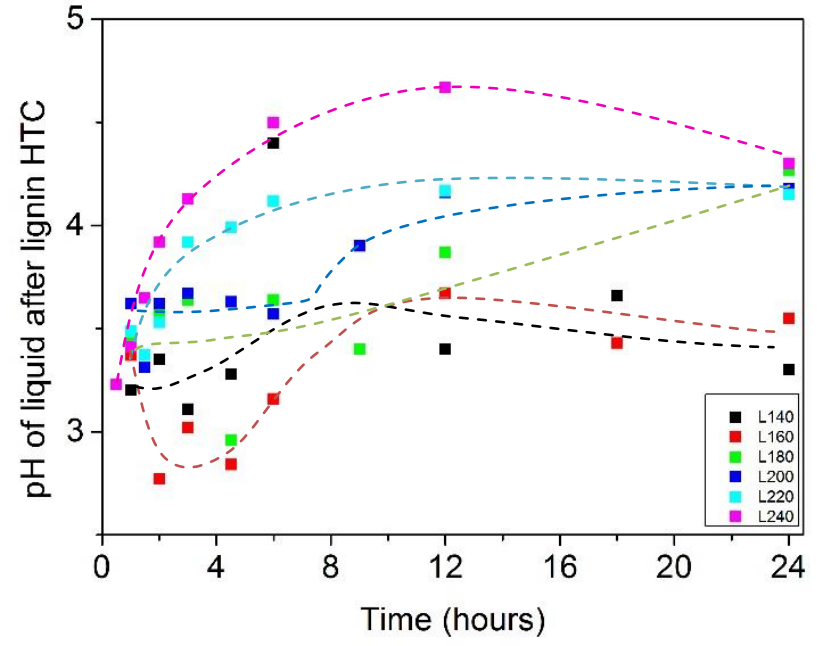

(b)

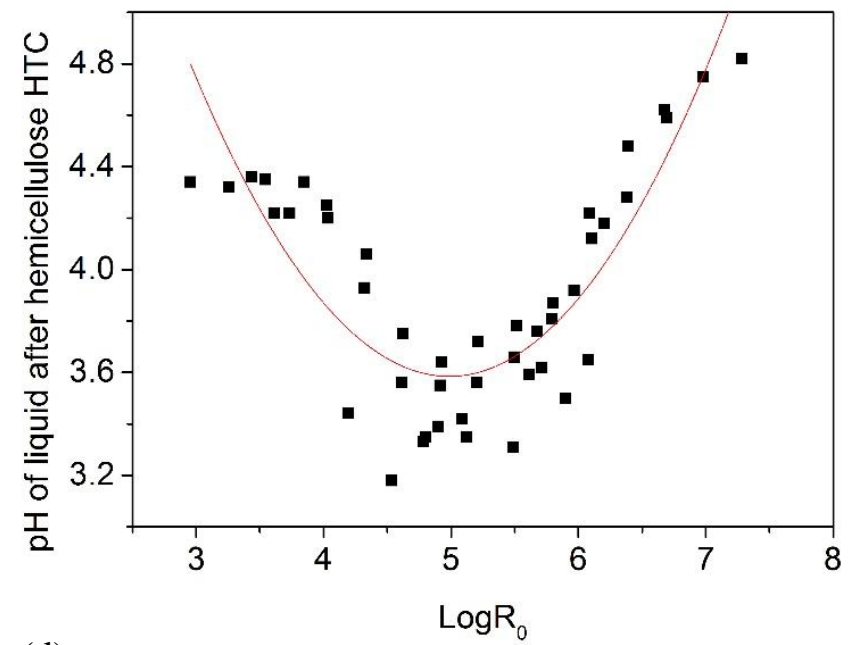

(d)

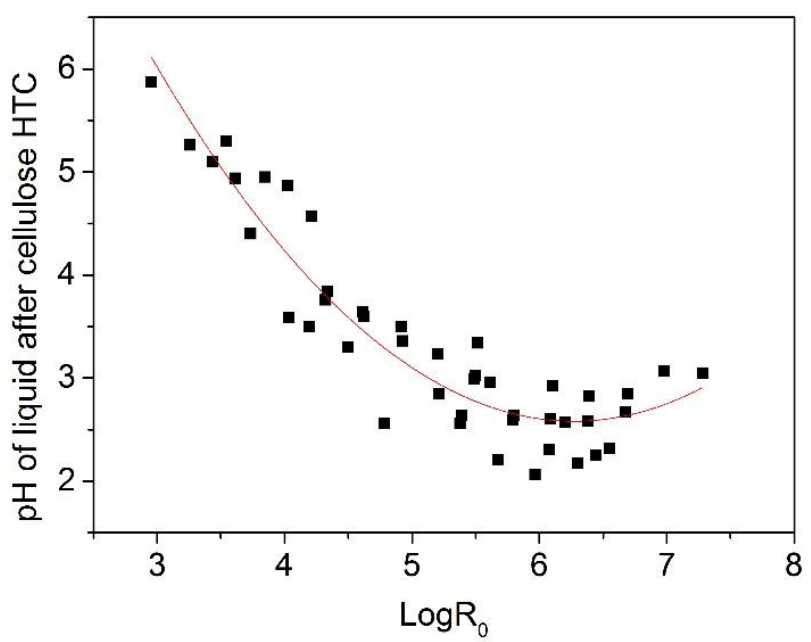

(f)

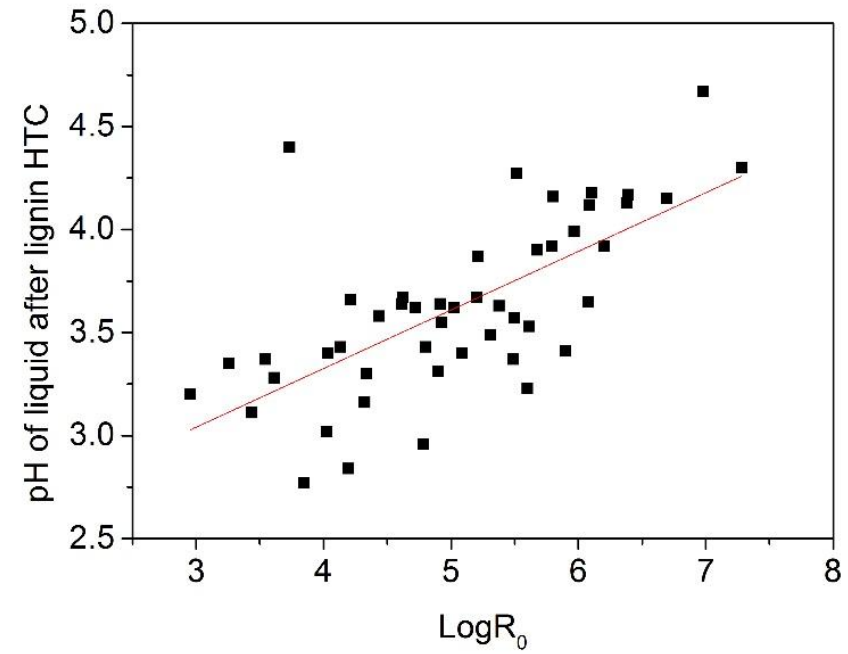

202 Figure 1. Final $\mathrm{pH}$ of liquid fractions as a function of time and temperature (left row),

203 and as a function of severity (right row), measured after HTC of: (a) and (b)

204 hemicellulose; (c) and (d) cellulose; (e) and (f) lignin. 
Table 1. Values of the parameters of Eq. (6) after fitting the data of Fig. 1b, 1d and 1f.

\begin{tabular}{llll}
\hline Biomass component (BC) & $\boldsymbol{p}_{\boldsymbol{1}}$ & $\boldsymbol{p}_{2}$ & $\boldsymbol{p}_{3}$ \\
\hline Cellulose & 15.20 & -4.04 & 0.32 \\
Lignin & 2.19 & 0.28 & - \\
Hemicellulose & 10.90 & -2.94 & 0.29 \\
\hline
\end{tabular}

206

\subsection{Yield to hydrochar}

208 The hydrochar yield from hemicellulose $\left(Y_{H C, H}\right)$ at high severity was lower than that 209 of cellulose and lignin (compare Fig. 2a, 2c and 2e), and the corresponding weight loss

210 also occurred at much lower severity. The yield was indeed around 35\% above a 211 severity of $4.5-5$, and roughly stabilised for higher severity values (Fig. 2a). It is also 212 possible that the curve goes through a minimum at a severity close to 5 , as suggested by 213 Fig. $2 b$ showing a slight maximum of liquid fraction, but the natural scattering of the 214 data doesn't allow any firm conclusion about this. Moreover, solid and liquid yields are 215 not necessarily directly related with each other since hydrochars may have retained 216 water bound to their structure, and gases may also have formed (see next subsection). 
(a)

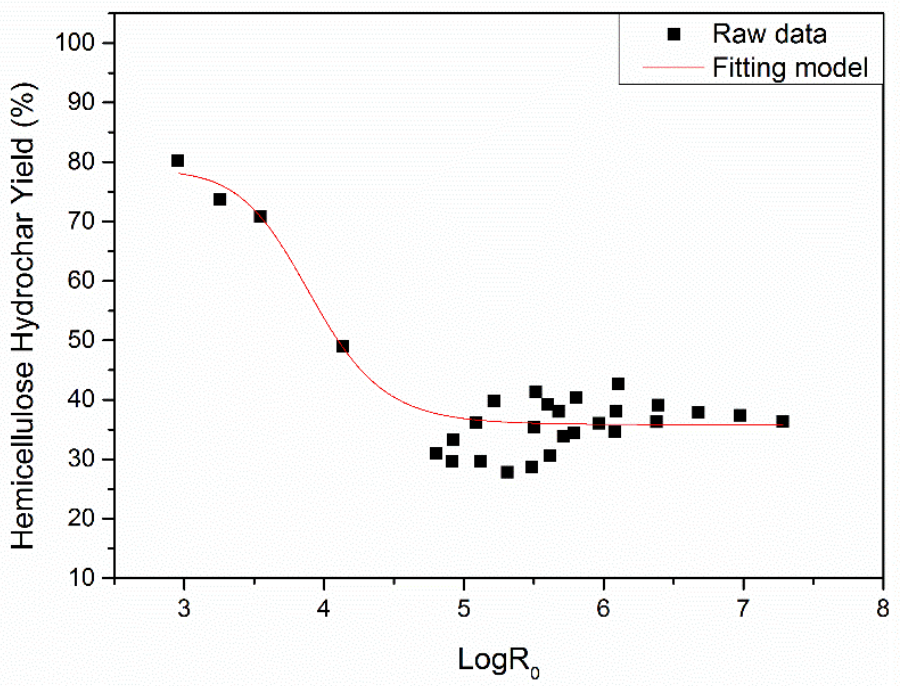

(c)

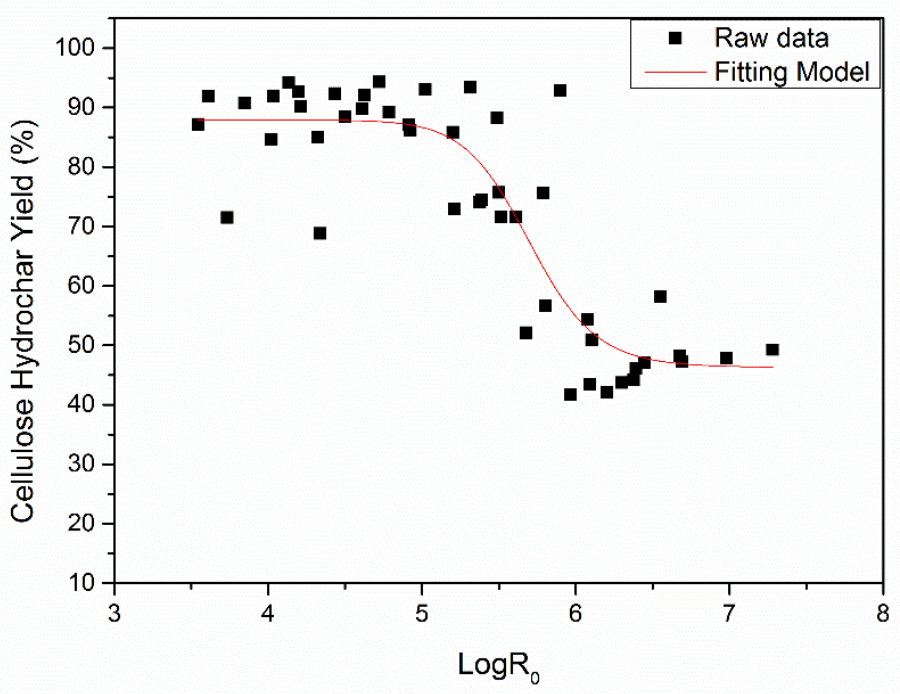

(e)

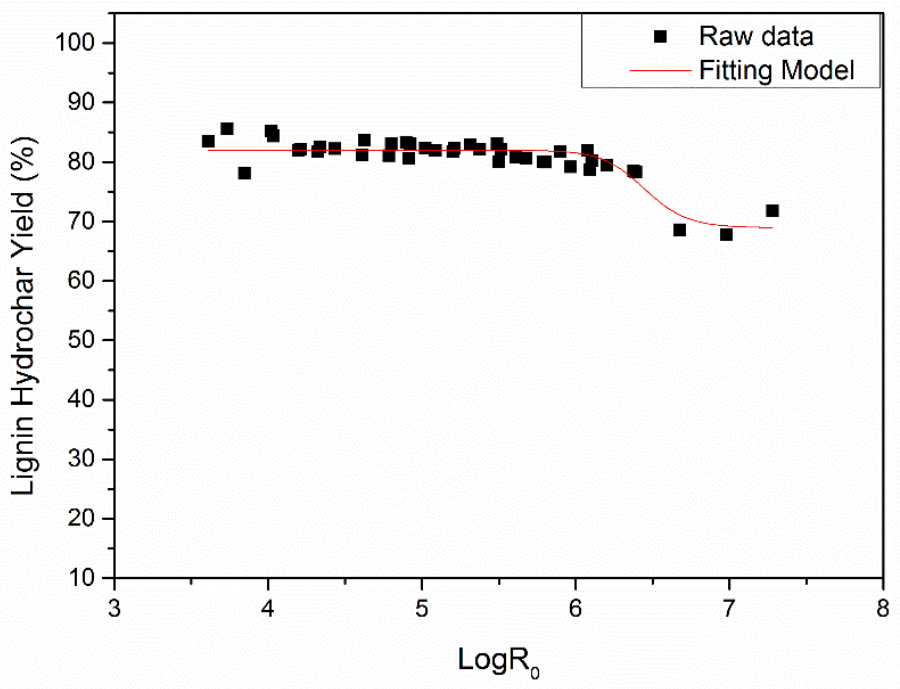

(b)

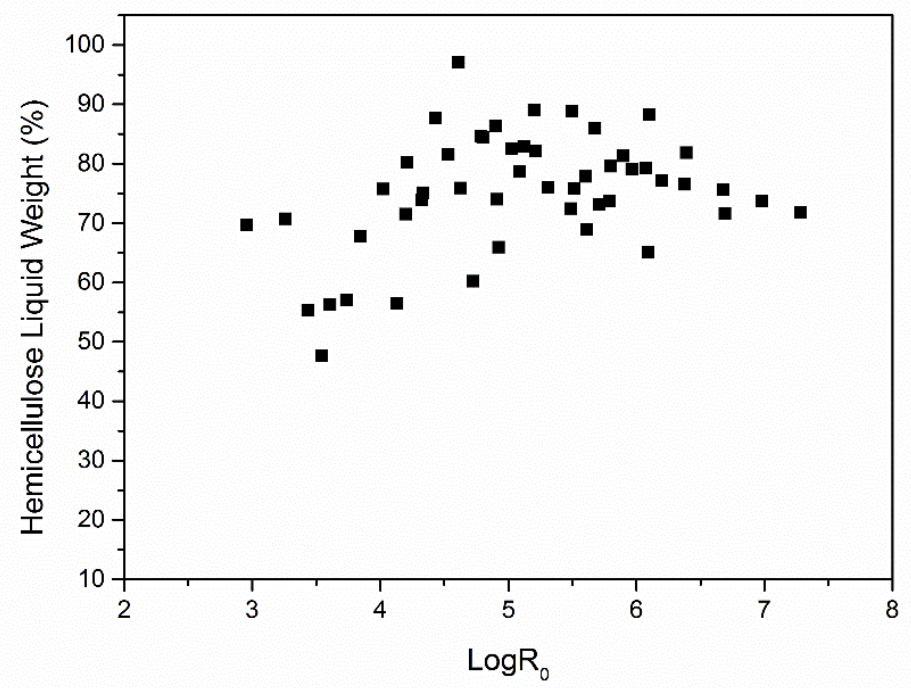

(d)

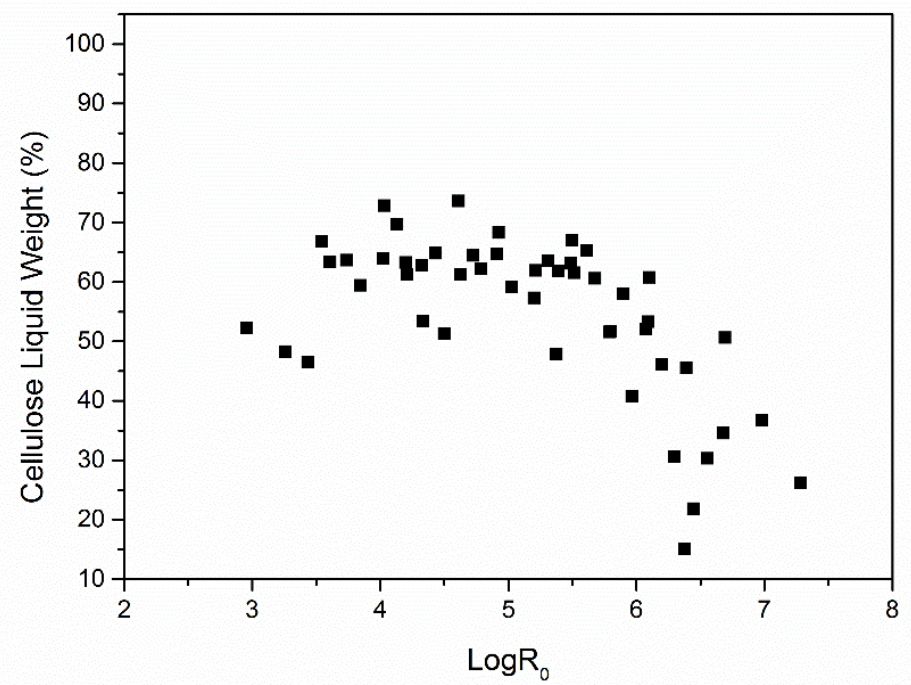

(f)

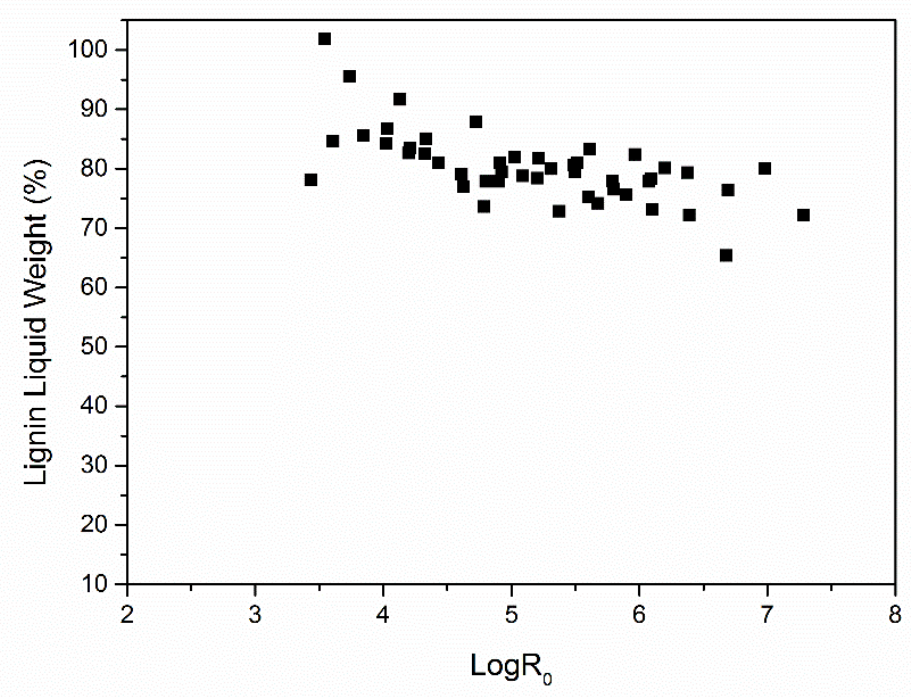

218 Figure 2. Yields of hydrochar (left row) and of liquid fraction (right row) as a function of

219 severity, measured after HTC of: (a) and (b) hemicellulose; (c) and (d) cellulose; (e) and

220 (f) lignin. The red lines are fits of Eq. (7) to the experimental data. 
At low severity, cellulose produced the highest amount of HC since the yield was as high as $88 \%$, on average. The weight loss stabilised around $46 \%$ at a severity around 6.5, i.e., higher than for hemicellulose. Moreover, the weight loss really started at a severity above 5.5, whereas hemicellulose lost weight from the mildest conditions. This finding is explained by the higher stability of cellulose that remained almost intact until $220^{\circ} \mathrm{C}$, above which degradation began (Fig. 2c).

Lignin was also quite stable since the $\mathrm{HC}$ yield was around $81 \%$ at low severity, on average, and remained constant up to temperature and time as high as $220^{\circ} \mathrm{C}$ and $12 \mathrm{~h}$, respectively, corresponding to a severity close to 6.5 (Fig. 2e). Such a yield is a bit lower than that of cellulose in the same conditions because part of the lignin is soluble in water (Overend and Chornet, 1987). Anyway, a lower weight loss than for the previous BCs was observed beyond a severity of 6.5 and quickly seemed to stabilise to around $69 \%$, which was the highest value of the 3 BCs in the most severe conditions.

A kinetic model able to account for the aforementioned trends was applied to the data of Fig. 2a, 2c, and 2e. This model, known as Cross model (Cross, 1965) and described by Eq. (7), has been extensively applied to rheological studies but, to the best of our knowledge, it is the first time that it is applied to hydrothermal carbonisation. It reads:

$$
Y_{H C, B C}=\frac{Y_{0}+Y_{\infty}(k S)^{m}}{1+(k S)^{m}}
$$

where $Y_{H C, B C}$ is the hydrochar yield at a given severity, $Y_{0}$ and $Y_{\infty}$ are the initial and final hydrochar yields, and $m$ and $k$ are parameters accounting for both the slope of the yield drop and the severity value at which the drop starts, respectively. The red lines in Fig. $2 \mathrm{a}, 2 \mathrm{c}$ and $2 \mathrm{e}$ show the fits of Eq. (7) to the experimental data. The corresponding adjustable parameters are given in Table 2 for hemicellulose, cellulose and lignin. This 
table also includes the coefficient of determination for the three raw materials,

246 demonstrating the good fitting despite the data scattering.

Table 2. Values of the parameters of Eq. (7) after fitting the data of Fig. 2a, 2c and 2e.

\begin{tabular}{llllll}
\hline Raw material & $Y_{0}(\%)$ & $Y_{\infty}(\%)$ & $k$ & $m$ & $R^{2}$ \\
\hline Hemicellulose & 77 & 35 & 0.25 & 21.33 & 0.89 \\
Cellulose & 88 & 46 & 0.17 & 26.42 & 0.77 \\
Lignin & 81 & 69 & 0.16 & 46.46 & 0.79 \\
\hline
\end{tabular}

\subsection{Yield to liquid phase}

As observed in Fig. 2, the yields of solid and liquid phases are not strictly correlated

with each other. On the one hand, the amount of liquid produced should increase because of the loss of water from biomass but, on the other hand, volatile compounds are likely to be released in the gas phase.

Concerning hemicellulose, the decrease of $\mathrm{HC}$ yield was related to the increase of liquid yield until a severity around 5, and the latter remained constant or decreased very slightly at higher severity (Fig. 2b), suggesting that no or negligible amount of gas was produced. When cellulose was submitted to HTC, the liquid fraction was initially roughly constant until a severity of 5.5 , above which it decreased very significantly (Fig. 2d). Since the hydrochar yield also decreased, it can be deduced that more and more gas was produced when the conditions turned more severe. As for lignin, the liquid fraction decreased rather linearly with severity over the whole investigated range beginning, and all the more so at higher severity, as expected. 


\subsection{FU and 5-HMF production}

268 The production of FU and 5-HMF as a function of HTC time followed the same 269 behaviour, whatever the biomass compound investigated. Thus, at the lowest 270 temperature, FU and 5-HMF production increased monotonously with time. When the 271 HTC temperature increased, a peak of production clearly appeared and was shifted to 272 lower reaction times. Therefore, at the highest investigated temperature, the highest 273 concentration of FU and 5-HMF was obtained in less than $1 \mathrm{~h}$. All these features are 274 shown in Fig. 3. Those trends were more complex than the ones observed above for the changes of $\mathrm{pH}$ and yields of hydrochar and liquid fraction, hence the production of FU and 5-HMF as a function of severity were much more scattered than in Fig. 1 and 2. However, a peak of production was still visible in the range of severity $3.5-4.5$. Fig. 4 278 shows the example of FU production from cellulose, hemicellulose and lignin.

279 According to Fig. 3 and 4, the highest concentration peak of FU was obtained from 280 hemicellulose, followed by cellulose and, far behind, lignin. On the contrary, the peak of 5-HMF concentration was the highest for cellulose, followed by hemicellulose and

282 finally lignin (see again Fig. 3). These results are logical since the precursors of FU and 283 5-HMF are xylans and glucoses, respectively, as they are the main structural units of 284 hemicellulose and cellulose, respectively. FU and 5-HMF production from lignin was thus not expected, and might be due to remaining polysaccharides present as impurities. 
(a)

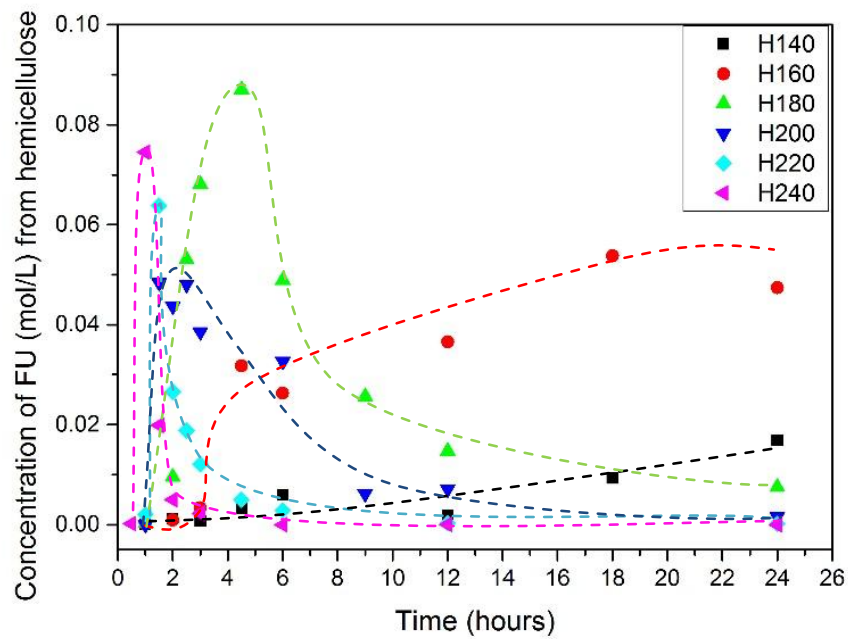

(c)

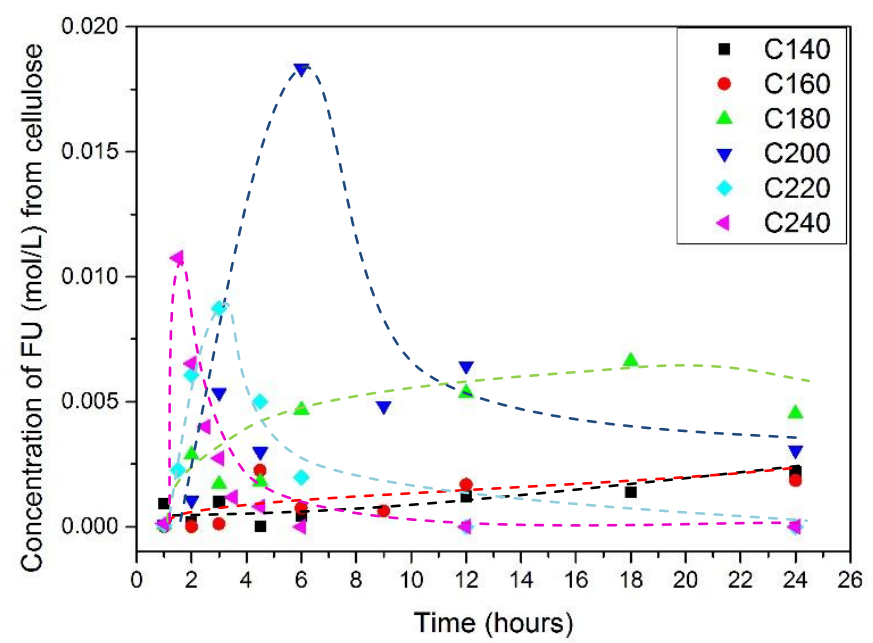

(e)

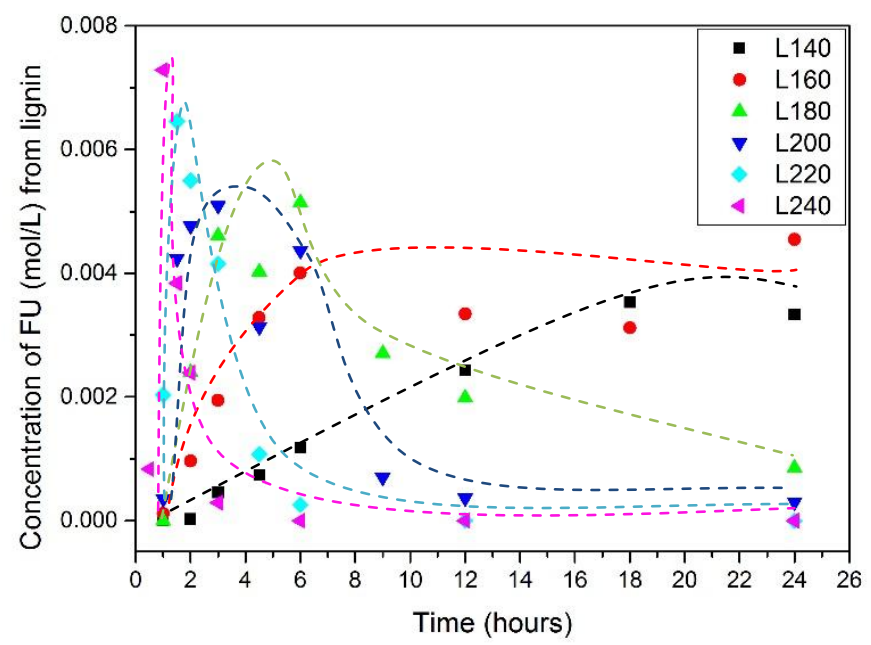

(b)

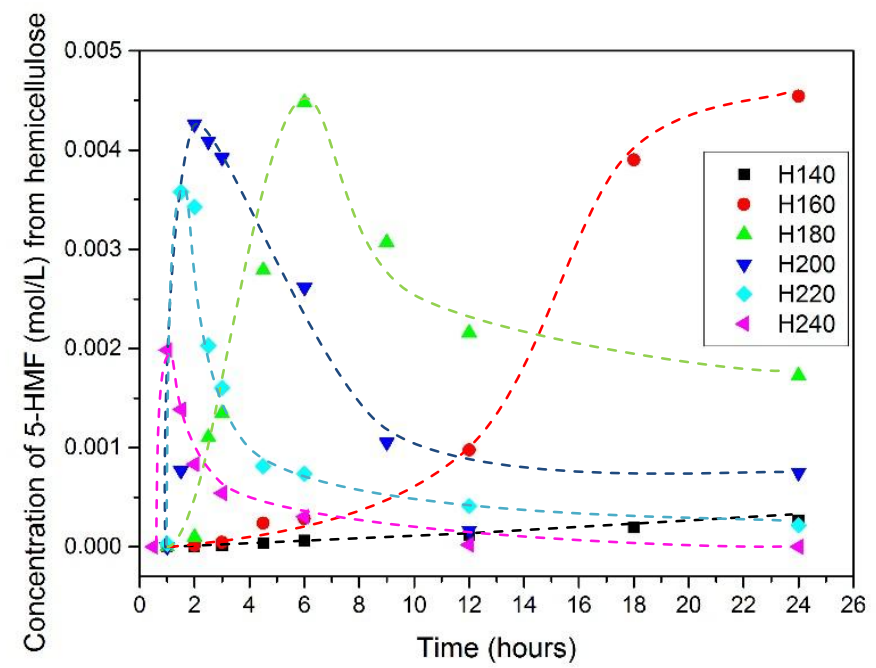

(d)

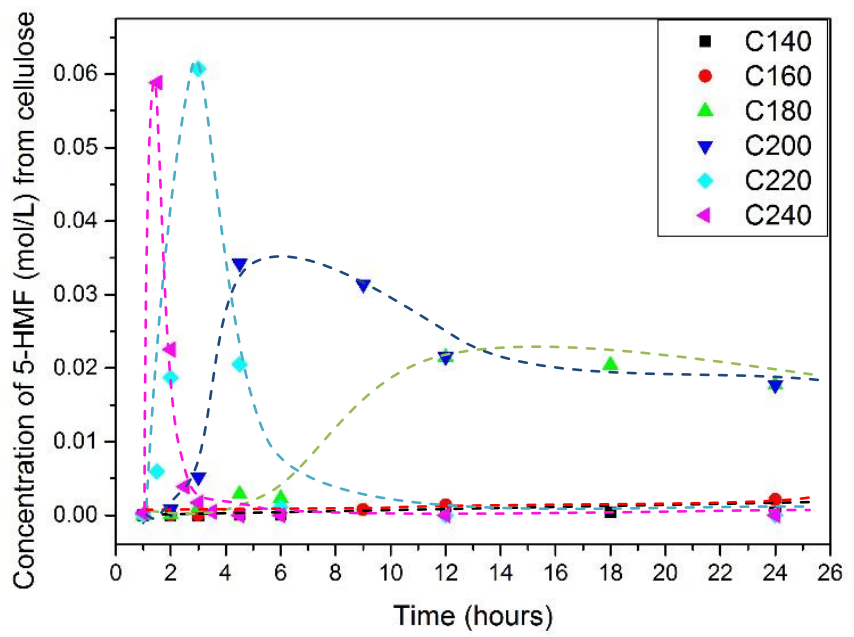

(f)

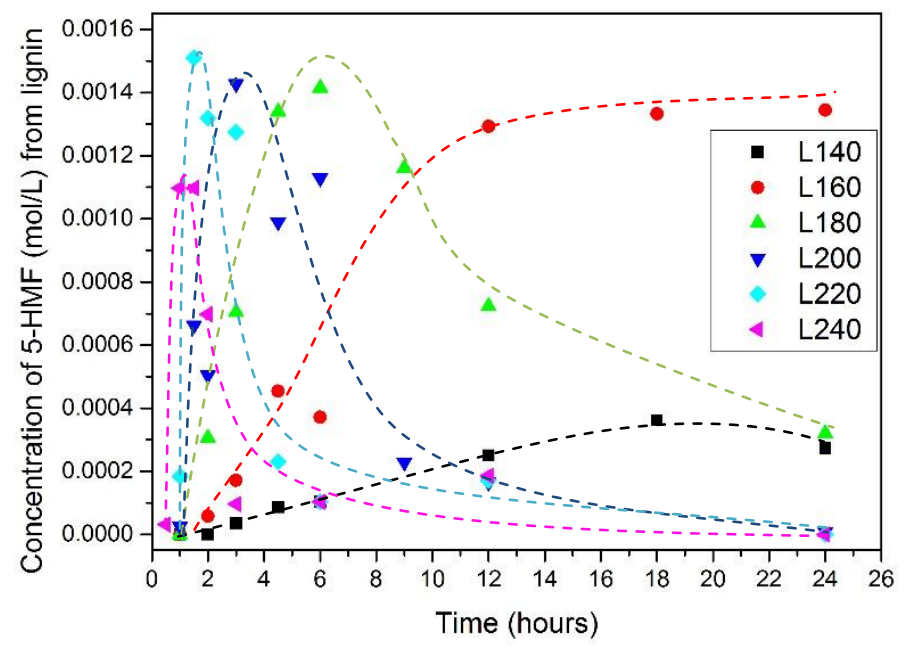

287 Figure 3. Molar concentration of FU (left row) and 5-HMF (right row) as a function of

288 reaction time, measured after HTC of: (a) and (b) hemicellulose; (c) and (d) cellulose;

289 (e) and (f) lignin. 

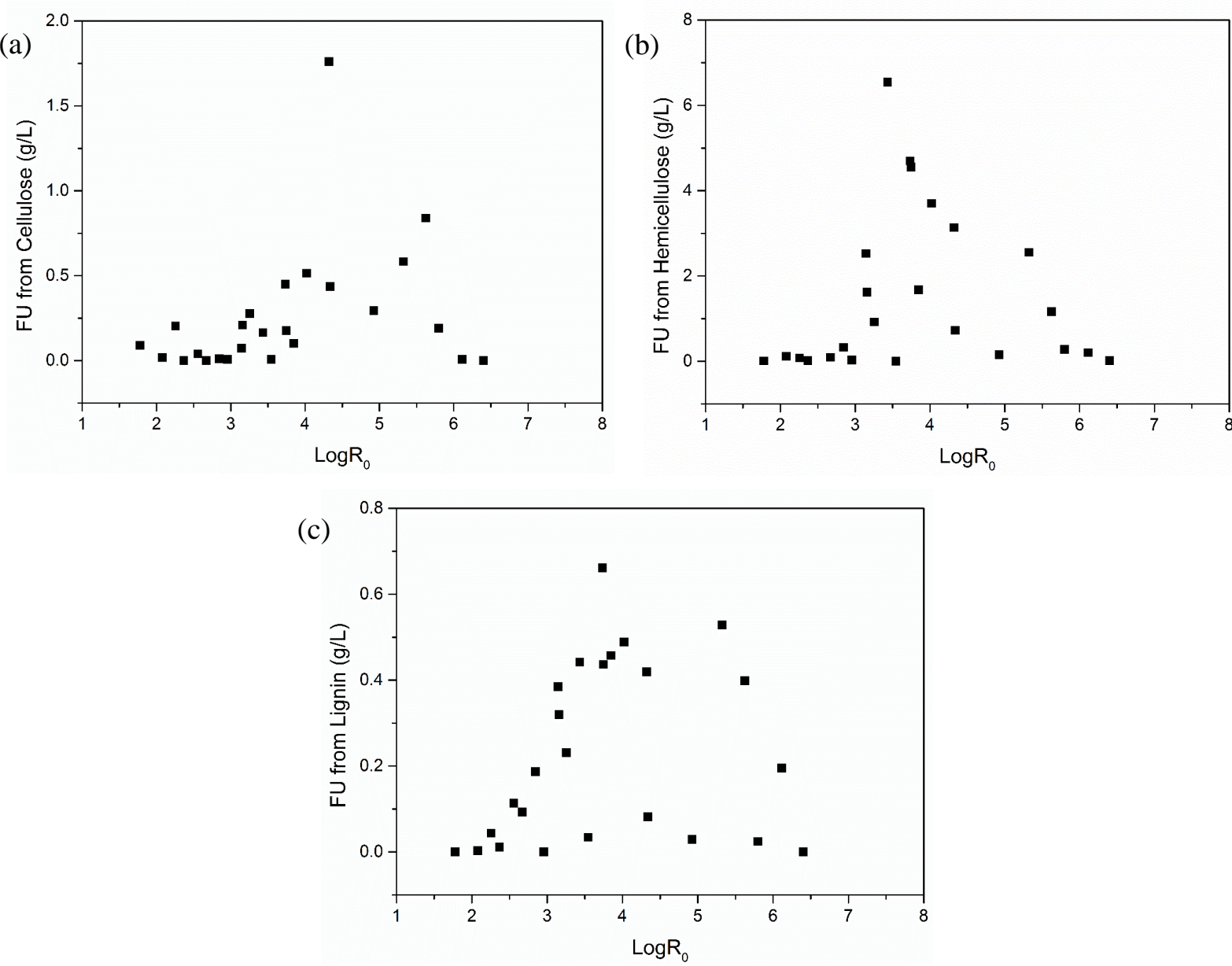

Figure 4. Production of FU by HTC of: (a) cellulose, (b) hemicellulose; and (c) lignin,

293 as function of severity.

\subsection{Reaction kinetics}

During HTC, FU and 5-HMF were produced but disappeared due to various

297 decomposition reactions. Two different models taking into account consecutive 298 reactions were considered in order to fit the kinetics of both production and 299 decomposition reactions.

300 The first one, referred to as model $\mathrm{A}$ in the following, considers FU and 5-HMF as

301 intermediates between simple sugars derived from BCs and final products, whether

302 those BCs are hemicellulose, cellulose or lignin. All reactions were assumed to be first-

303 order and are presented in Fig. 5 for FU and 5-HMF, respectively. 
MODEL A

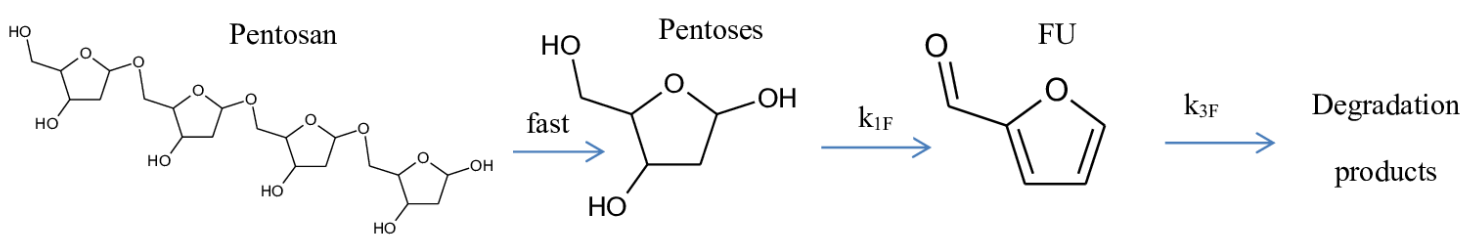

$$
C_{F U}=C_{B C} \cdot\left(\frac{k_{1 F}}{k_{3 F}-k_{1 F}}\right) \cdot\left[e^{-\left(k_{1 F}\right) \cdot t}-e^{-\left(k_{3 F}\right) \cdot t}\right]
$$

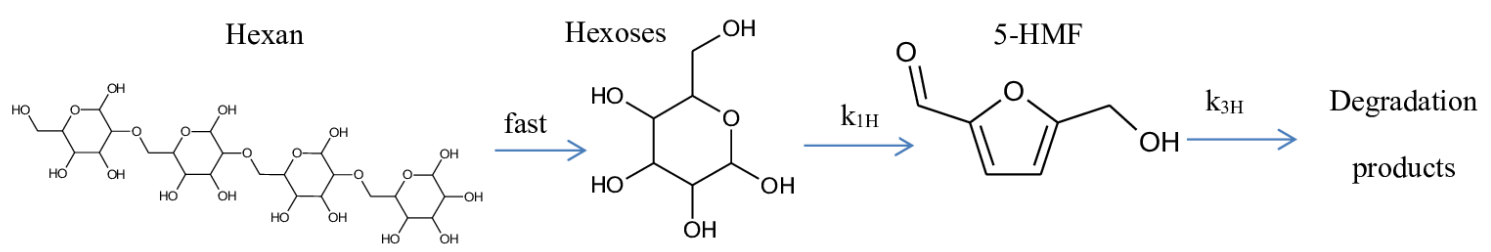

$$
C_{5-H M F}=C_{B C} \cdot\left(\frac{k_{1 H}}{k_{3 H}-k_{1 H}}\right)\left[e^{-\left(k_{1 H}\right) \cdot t}-e^{-\left(k_{3 H}\right) \cdot t}\right]
$$

MODEL B

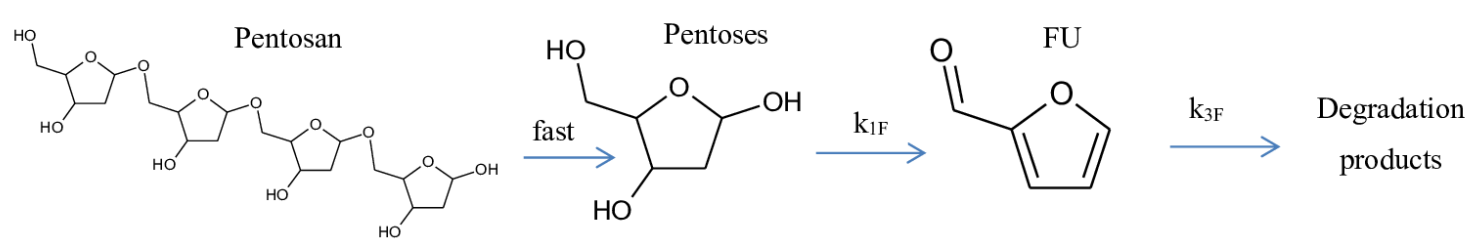

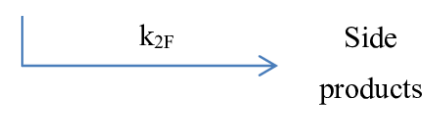

$$
C_{F U}=C_{B C} \cdot\left(\frac{k_{1 F}}{k_{3 F}-k_{1 F}-k_{2 F}}\right) \cdot\left[e^{-\left(k_{1 F}+k_{2 F}\right) \cdot t}-e^{-k_{3 F} \cdot t}\right]
$$

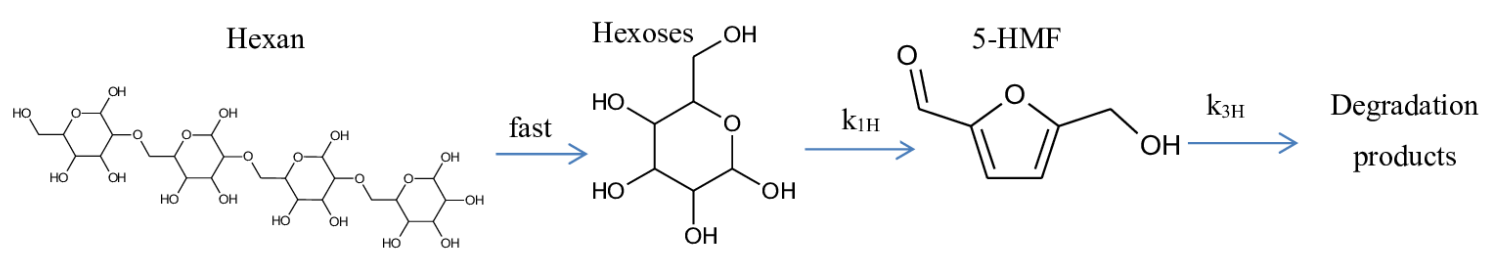

$$
\begin{gathered}
\mathrm{k}_{2 \mathrm{H}} \begin{array}{c}
\text { Side } \\
\text { products }
\end{array} \\
C_{5-H M F}=C_{B C} \cdot\left(\frac{k_{1 H}}{k_{3 H}-k_{1 H}-k_{2 H}}\right) \cdot\left[e^{-\left(k_{1 H}+k_{2 H}\right) \cdot t}-e^{-k_{3 H} \cdot t}\right]
\end{gathered}
$$

305 Figure 5. Models A and B Governing pentoxan and hexan reactions. Model B takes into 306 account competitive reactions to give side products, other than FU and 5-HMF.

307 The second model, called model $\mathrm{B}$, considers, in addition to the same 308 aforementioned successive reactions, the existence of side reactions leading to the production of other species. In this case, all reactions were assumed first-order too. Side reactions were suggested by Liu et al. (2014), who showed that better fits to the kinetics 
311 data were obtained compared to the case of the simple model of consecutive reactions

312 (model A). In other studies, an intermediate compound for each process has been 313 postulated, but could never be isolated or identified (Marcotullio, 2011). Model B, 314 taking into account side reactions, is also sketched in Fig. 5.

315 Herein, it is considered that pentosan directly gives furfural and that hexan gives 5316 HMF with kinetic constants $k_{l F}$ and $k_{1 H}$, respectively. FU and 5-HMF decompose to 317 final products with kinetic constants $k_{3 F}$ and $k_{3 H}$, respectively. Pentosan and hexan also 318 react by side reactions with constants $k_{2 F}$ and $k_{2 H}$, respectively. After resolution of the 319 corresponding differential kinetics equations, FU and 5-HMF concentrations can be expressed by Eq. (8) and (9) for model A, respectively, and by Eq. (10) and (11) for model $\mathrm{B}$, respectively. In those equations, $C_{F U}, C_{5-H M F}$ and $C_{B C}$ are the initial concentrations of FU, 5-HMF and $\mathrm{BC}$ (cellulose, hemicellulose or lignin). Having in mind that xylans and glucoses are the main structural units of hemicellulose and cellulose, respectively. We assumed that BCs decomposed following exclusively model A or model B. This assumption could be less logic for lignin but it is necessary to take into account that here, the fraction of lignin considered is that giving FU and 5-HMF and corresponding to polysaccharides present in lignin as impurities. As it was seen in Fig. 2e, lignin produced more hydrochar, in the whole range of severities tested, than $\mathrm{C}$ and $\mathrm{H}$ because $\mathrm{L}$ is an aromatic molecule prone to condensate as it happens with other polyphenolic compounds as tannins (Braghiroli et al., 2014, 2017, Selmi et al., 2018).

By application of these two models, the different constants were obtained, and 332 activation energy $\left(E_{a}\right)$ and pre-exponential factor $\left(k_{0}\right)$ were also determined by 333 application of Arrhenius' Eq. (5) to each kinetic constant. Examples of those Arrhenius 334 fits can be seen in Fig. 6. 

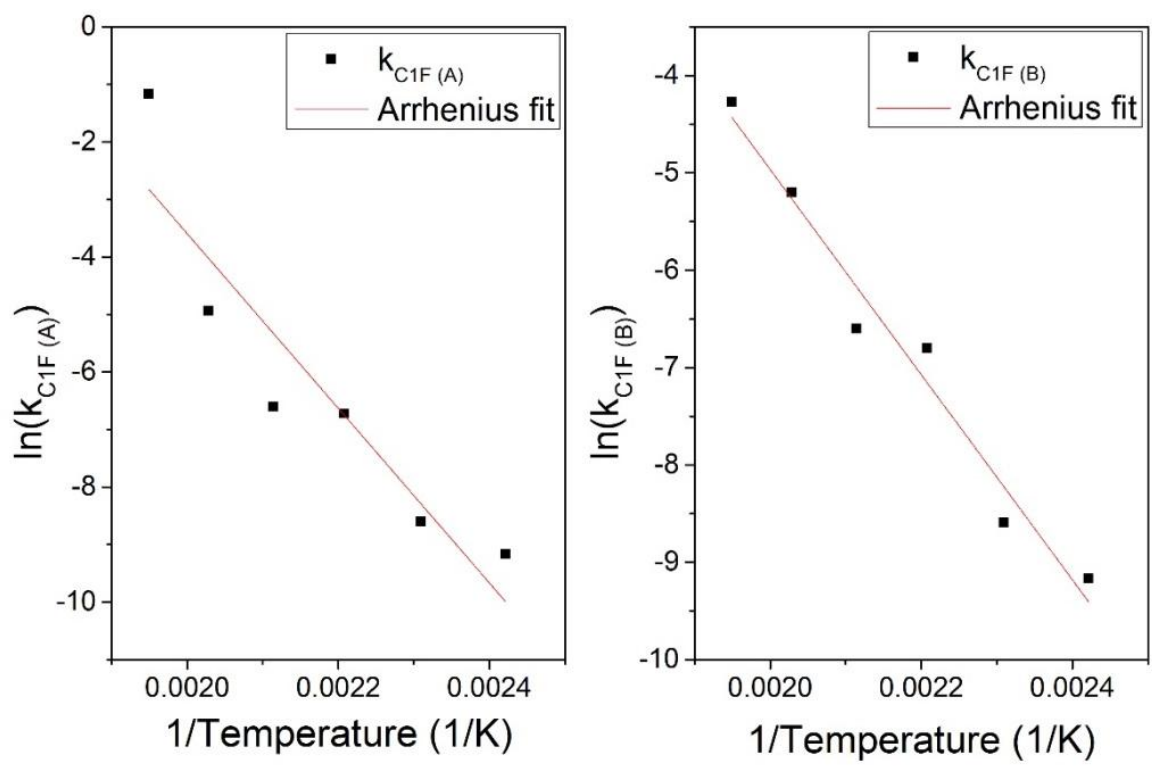

Figure 6. Examples of Arrhenius fitting applied to kinetic constants for cellulose.

Table 3. Activation energy $\left(E_{a}, \mathrm{~kJ} \cdot \mathrm{mol}^{-1}\right)$ and pre-exponential factor $\left(k_{0}, \mathrm{~s}^{-1}\right)$ for each $\mathrm{FU}$ and 5-HMF reaction constant in models $\mathrm{A}$ and $\mathrm{B}$.

\begin{tabular}{ccccccc}
\hline & \multicolumn{2}{c}{ Hemicellulose } & \multicolumn{2}{c}{ Cellulose } & \multicolumn{2}{c}{ Lignin } \\
& Model A & Model B & Model A & Model B & Model A & Model B \\
\cline { 1 - 3 } FU & & & & & & \\
\cline { 1 - 2 }$k_{0,1 F}$ & $2.68 \mathrm{E}+7$ & $2.93 \mathrm{E}+4$ & $1.18 \mathrm{E}+8$ & $2.69 \mathrm{E}+03$ & $1.87 \mathrm{E}+10$ & $5.94 \mathrm{E}+01$ \\
$E_{a, 1 F}$ & 109.52 & 85.48 & 126.25 & 87.54 & 138.34 & 69.41 \\
$k_{0,2 F}$ & & $3.88 \mathrm{E}+4$ & & $1.28 \mathrm{E}+04$ & & $6.90 \mathrm{E}+03$ \\
$E_{a, 2 F}$ & & 78.67 & & 77.29 & & 71.60 \\
$k_{0,3 F}$ & $3.75 \mathrm{E}+8$ & $2.62 \mathrm{E}+4$ & $2.50 \mathrm{E}+11$ & $1.37 \mathrm{E}+04$ & $5.53 \mathrm{E}+12$ & $6.94 \mathrm{E}+03$ \\
$E_{a, 3 F}$ & 108.22 & 76.56 & 136.52 & 77.49 & 138.71 & 71.56 \\
$\mathbf{5 - H M F}$ & & & & & \\
\cline { 1 - 2 }$k_{0,1 H}$ & $2.22 \mathrm{E}+13$ & $2.16 \mathrm{E}+04$ & $4.83 \mathrm{E}+15$ & $1.09 \mathrm{E}+11$ & $2.09 \mathrm{E}+11$ & $1.47 \mathrm{E}+01$ \\
$E_{a, 1 H}$ & 171.96 & 97.52 & 176.89 & 152.49 & 155.53 & 71.57 \\
$k_{l, 2 H}$ & & $1.31 \mathrm{E}+03$ & & $2.20 \mathrm{E}+09$ & & $8.78 \mathrm{E}+01$ \\
$E_{a, 2 H}$ & & 66.01 & & 126.70 & & 55.79 \\
$k_{0,3 H}$ & $5.08 \mathrm{E}+19$ & $1.26 \mathrm{E}+03$ & $9.33 \mathrm{E}+13$ & $2.31 \mathrm{E}+09$ & $9.38 \mathrm{E}+13$ & $3.44 \mathrm{E}+02$ \\
$E_{a, 3 H}$ & 207.03 & 65.82 & 179.30 & 126.56 & 152.77 & 61.50 \\
\hline
\end{tabular}



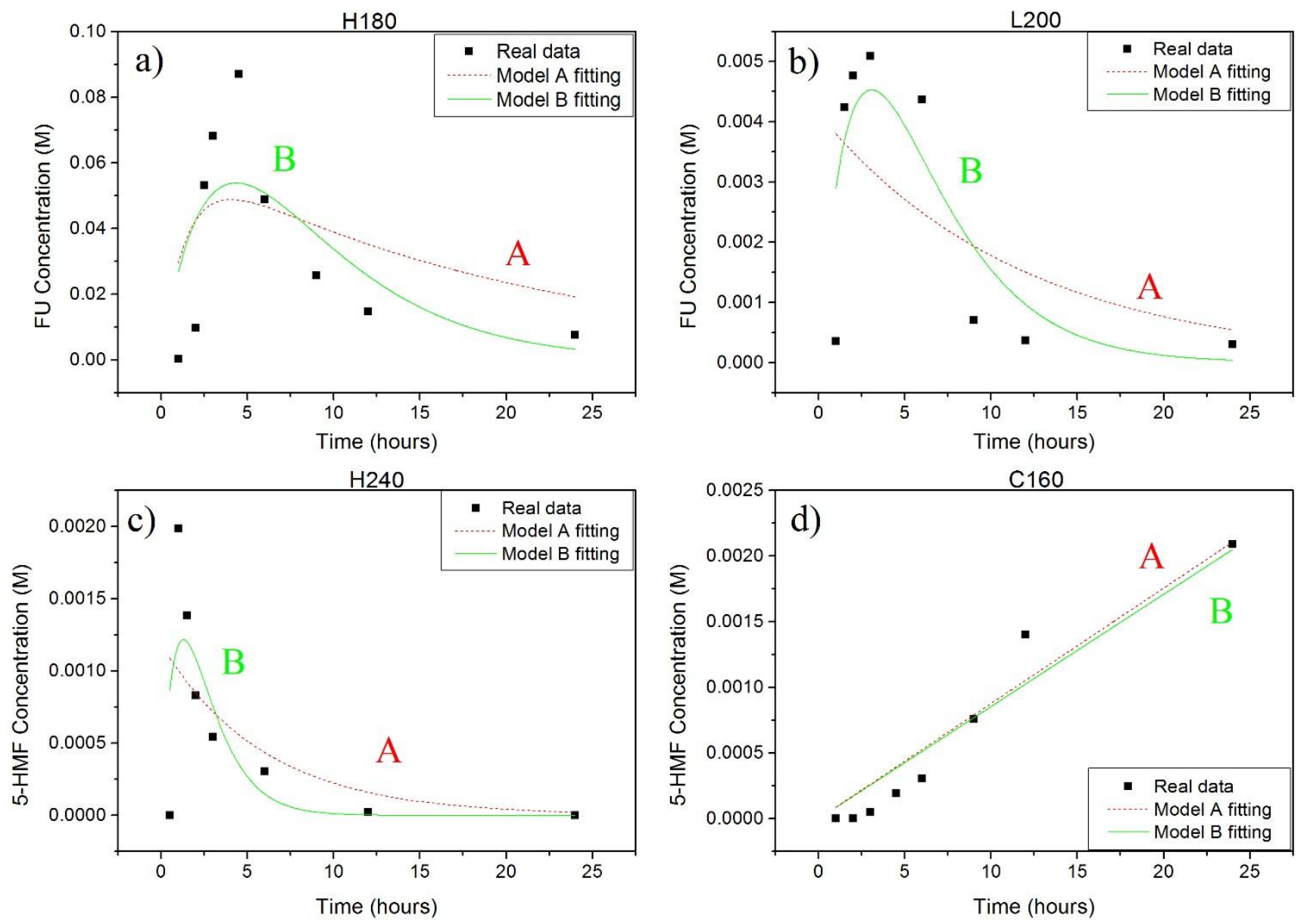

3.

347 Figure 7. Variation of FU (a) and (b) and 5-HMF (c) and (d) concentration with time for

348 a) $\mathrm{H}$ submitted at $180{ }^{\circ} \mathrm{C}$, (b) L submitted at $200^{\circ} \mathrm{C}$, (c) $\mathrm{H}$ submitted at $240{ }^{\circ} \mathrm{C}$, and (d)

$349 \mathrm{C}$ submitted at $160^{\circ} \mathrm{C}$. Fitting with models $\mathrm{A}$ and $\mathrm{B}$ to the experimental data are

350 included as dashed and continuous lines, respectively. 

conversion. These results are compared to those obtained in the present study for

354 hemicellulose, to which model B was applied. Most published works reported higher $E_{a}$

355 values than those obtained here (Danon et al., 2014, Liu et al., 2014, Jing and Lü, 2007),

356 which suggests that the effect of temperature observed herein is not as high as that

357 reported in other studies. However, results regarding the same temperature range as in

358 the present work led to lower $E_{a}$, thus in agreement with our findings (Kim et al., 2011).

359 Concerning the pre-exponential factors, there is no obvious agreement between the

360 various available results. The reason might be related to the too different ranges of time,

361 temperature or initial concentrations used in this study with respect to those reported in

362 other published works.

363

364 Table 4. Activation energies $\left(E_{a}, \mathrm{~kJ} \mathrm{~mol}^{-1}\right)$ and pre-exponential factors $\left(k_{0}, \mathrm{~s}^{-1}\right)$ for 365 xylose conversion into $\mathrm{FU}\left(k_{1}\right)$, side products $\left(k_{2}\right)$ and degradation products $\left(k_{3}\right)$ reported 366 herein and in the literature.

\begin{tabular}{|c|c|c|c|c|c|c|c|c|}
\hline \multirow[t]{2}{*}{ Ref } & \multirow[t]{2}{*}{ Catalyst } & \multirow[t]{2}{*}{$\mathrm{T}\left({ }^{\circ} \mathrm{C}\right)$} & \multicolumn{2}{|c|}{$k_{I F}\left(\mathrm{~s}^{-1}\right)$} & \multicolumn{2}{|c|}{$k_{2 F}\left(\mathrm{~s}^{-1}\right)$} & \multicolumn{2}{|c|}{$k_{3 F}\left(\mathrm{~s}^{-1}\right)$} \\
\hline & & & $\begin{array}{l}k_{0,1 F} \\
\left(\mathrm{~s}^{-1}\right) \\
\end{array}$ & $\begin{array}{c}E_{a, 1 F} \\
\left(\mathrm{~kJ} \cdot \mathrm{mol}^{-1}\right)\end{array}$ & $\begin{array}{l}k_{0,2 F} \\
\left(\mathrm{~s}^{-1}\right) \\
\end{array}$ & $\begin{array}{c}E_{a, 2 F} \\
\left(\mathrm{~kJ} \cdot \mathrm{mol}^{-1}\right)\end{array}$ & $\begin{array}{l}k_{0,3 F} \\
\left(\mathrm{~s}^{-1}\right) \\
\end{array}$ & $\begin{array}{c}E_{a, 3 F} \\
\left(\mathrm{~kJ} \cdot \mathrm{mol}^{-1}\right) \\
\end{array}$ \\
\hline This study & None & $140-240$ & $2.94 \mathrm{E}+04$ & 85.5 & $3.89 \mathrm{E}+04$ & 78.7 & $1.37 \mathrm{E}+04$ & 76.56 \\
\hline $\begin{array}{c}\text { Danon et al., } \\
2014\end{array}$ & $\begin{array}{c}\mathrm{HCl} \& \\
\mathrm{NaCl}\end{array}$ & $160-200$ & $1.05 \mathrm{E}-03$ & 133.3 & $2.30 \mathrm{E}-04$ & 125.8 & - & - \\
\hline $\begin{array}{l}\text { Liu et al., } \\
2014\end{array}$ & $\begin{array}{l}\text { Acetic } \\
\text { acid }\end{array}$ & $150-190$ & $9.81 \mathrm{E}+12$ & 156.6 & $2.94 \mathrm{E}+12$ & 149 & $3.69 \mathrm{E}+09$ & 115.1 \\
\hline $\begin{array}{c}\text { Jing and Lü, } \\
2007\end{array}$ & None & $180-220$ & $6.28 \mathrm{E}+06$ & 111.47 & $1.40 \mathrm{E}+10$ & 143.14 & $3.31 \mathrm{E}+01$ & 58.84 \\
\hline $\begin{array}{c}\text { Kim et al., } \\
2011\end{array}$ & None & $140-240$ & $2.05 \mathrm{E}+01$ & 76.6 & $\begin{array}{r}3.31 \mathrm{E}-1 / \\
2.66 \mathrm{E}+12 * \\
\end{array}$ & $58.8 / 154^{*}$ & $4.92 \mathrm{E}-16$ & 24.2 \\
\hline
\end{tabular}

367 *Two values are presented since the reaction is a combination between first and second order 368 reaction (first and second values, respectively). 
376 Table 5. Activation energies $\left(E_{a}, \mathrm{~kJ} \mathrm{~mol}^{-1}\right)$ and pre-exponential factors $\left(k_{0}, \mathrm{~s}^{-1}\right)$ for

377 hexose conversion into 5-HMF $\left(k_{1}\right)$, side products $\left(k_{2}\right)$ and degradation products $\left(k_{3}\right)$

378 reported herein and in the literature.

Table 5 shows the kinetic parameters obtained here for cellulose decomposition using model $\mathrm{B}$, compared to those available in the open literature for 5-HMF conversion. $E_{a}$ values were similar to those previously reported, but $k_{0}$ values were lower than those of previous works, probably due, again, to the wider range of temperatures studied in this present work.

\begin{tabular}{|c|c|c|c|c|c|c|c|c|c|}
\hline \multirow[t]{2}{*}{ Ref } & \multirow[t]{2}{*}{ Raw material } & \multirow[t]{2}{*}{ Catalyst } & \multirow[t]{2}{*}{$\mathbf{T}\left({ }^{\circ} \mathbf{C}\right)$} & \multicolumn{2}{|c|}{$k_{1 H}\left(\mathrm{~s}^{-1}\right)$} & \multicolumn{2}{|c|}{$k_{2 H}\left(\mathrm{~s}^{-1}\right)$} & \multicolumn{2}{|c|}{$k_{3 H}\left(\mathrm{~s}^{-1}\right)$} \\
\hline & & & & $\begin{array}{l}k_{0,1 H} \\
\left(\mathrm{~s}^{-1}\right)\end{array}$ & $\begin{array}{c}E_{a, 1 H} \\
\left(\mathrm{~kJ} \cdot \mathrm{mol}^{-1}\right)\end{array}$ & $\begin{array}{l}k_{0,2 H} \\
\left(\mathrm{~s}^{-1}\right)\end{array}$ & $\begin{array}{c}E_{a, 2 H} \\
\left(\mathrm{~kJ} \cdot \mathrm{mol}^{-1}\right)\end{array}$ & $\begin{array}{l}k_{0,3 H} \\
\left(\mathrm{~s}^{-1}\right)\end{array}$ & $\begin{array}{c}E_{a, 3 H} \\
\left(\mathrm{~kJ} \cdot \mathrm{mol}^{-1}\right)\end{array}$ \\
\hline $\begin{array}{l}\text { This } \\
\text { study }\end{array}$ & $\begin{array}{l}\text { Microcrystalline } \\
\text { cellulose }\end{array}$ & $\begin{array}{l}\text { Non } \\
\text { catalysed }\end{array}$ & $140-240$ & $1.09 \mathrm{E}+11$ & 152.49 & $2.20 \mathrm{E}+09$ & 126.70 & $2.31 \mathrm{E}+09$ & 126.55 \\
\hline $\begin{array}{l}\text { Jing and } \\
\text { Lü, } 2008\end{array}$ & Glucose & $\begin{array}{l}\text { Non } \\
\text { catalysed }\end{array}$ & $180-220$ & $8.44 \mathrm{E}+07$ & 108.03 & $7.22 \mathrm{E}+10$ & 135.71 & $2.02 \mathrm{E}+06$ & 95.4 \\
\hline $\begin{array}{c}\text { Shen and } \\
\text { Wyman } \\
2012\end{array}$ & $\begin{array}{l}\text { Microcrystalline } \\
\text { cellulose }\end{array}$ & $\begin{array}{c}\text { Hydrochloric } \\
\text { acid }\end{array}$ & $180-200$ & $4.67 \mathrm{E}+13^{*}$ & 137 & - & - & $2.20 \mathrm{E}+15^{*}$ & 144.83 \\
\hline
\end{tabular}

$379 *$ Unit of $\mathrm{L} \cdot(\mathrm{mol} \cdot \mathrm{s})^{-1}$ instead of $\mathrm{s}^{-1}$ because proton concentration was not taken into account. 380

381

382

\section{.}


391 be seen that the maximum of vanillin and syringaldehyde production both appeared at a

392 similar severity around 5, whereas the maximum of acetosyringone was reached at a

393 severity close to 6.2. Above such optimal severity values, vanillin and syringaldehyde

394 concentrations dropped significantly whereas that of acetosyringone only decreased

395 moderately. Meanwhile, guaiacyl acetone and acetovanillone presented a linear increase

396 of concentration. Guaiacol, syringol and phenol concentrations also increased, but in a

397 somewhat exponential way. Finally, creosol was only produced at the highest severity,

398 at which its concentration also increased quite fast.

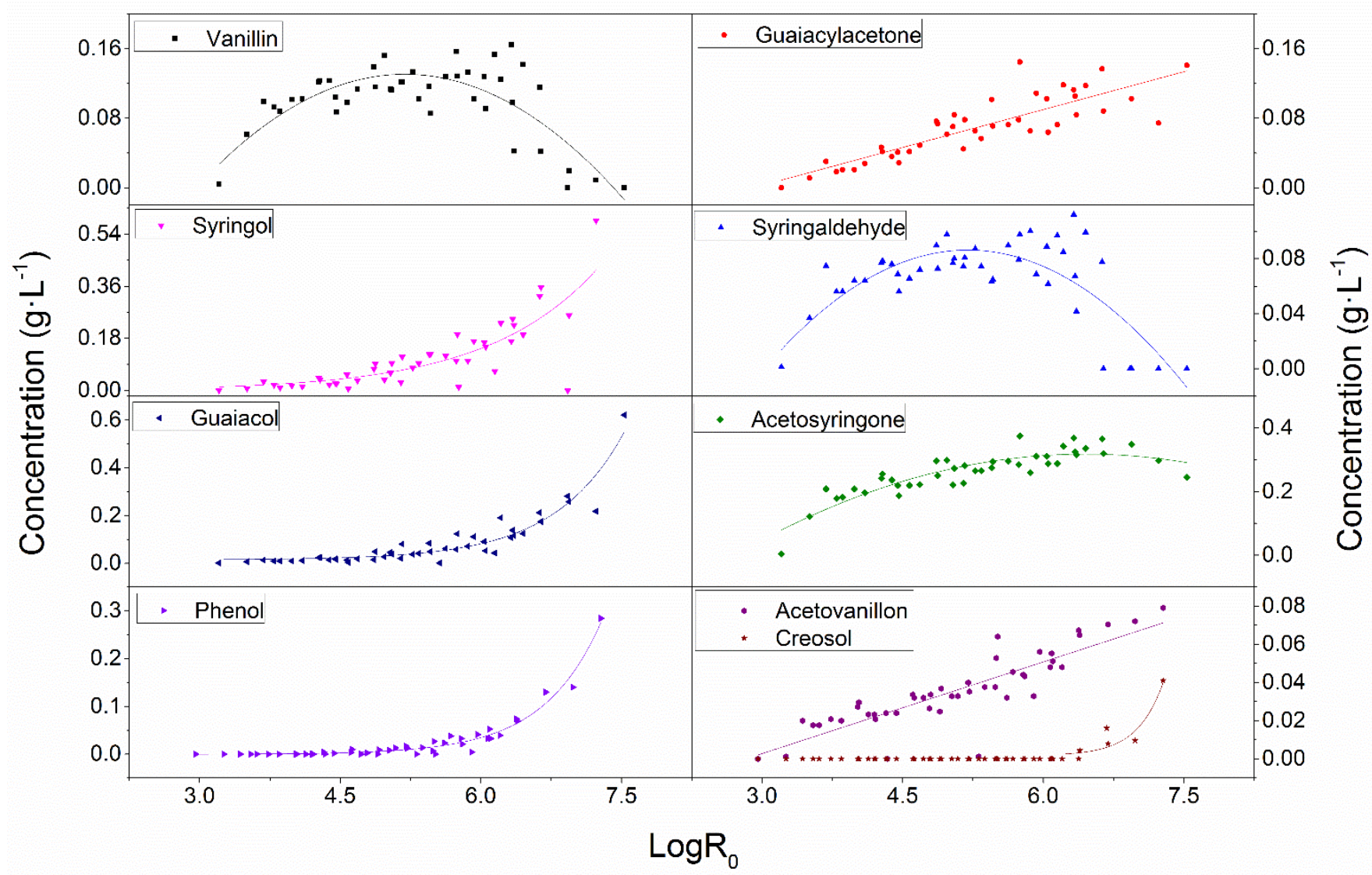

400 Figure 8. Concentration of the nine phenolic compounds studied in this work as a

401 function of severity. 
Regarding the exhibited behaviours, various fitting trends were found whose polynomial, linear or exponential character is accounted for by Eq. (12), (13) and (14),

405

406

407

408

409

410

411

412 respectively. The values of the corresponding parameters for each compound are given in Table 6, and may be use for predicting the production of phenolic compounds from lignin submitted to hydrothermal treatment at a given severity $\log R_{0}$.

$$
C_{\text {phenolic compound }}=a+b\left(\log R_{0}\right)+c\left(\log R_{0}\right)^{2}
$$

12 Table 6. Parameters from the fits of Eq. (12), (13) or (14) to the data of Fig. 8.

\begin{tabular}{|c|c|c|c|}
\hline \multirow[t]{3}{*}{ Phenolic Compound } & \multicolumn{3}{|c|}{ Parameters of the fits } \\
\hline & \multicolumn{3}{|c|}{ Polynomial } \\
\hline & $a$ & $b$ & $c$ \\
\hline Vanillin & -0.51 & 0.26 & -0.02 \\
\hline Syringaldehyde & -0.36 & 0.18 & -0.02 \\
\hline \multirow[t]{3}{*}{ Acetosyringone } & -0.56 & 0.28 & -0.02 \\
\hline & \multicolumn{3}{|c|}{ Linear } \\
\hline & \multirow{2}{*}{\multicolumn{2}{|c|}{$\begin{array}{c}\alpha \\
008\end{array}$}} & $\beta$ \\
\hline \multirow{4}{*}{$\begin{array}{l}\text { Guaiacylacetone } \\
\text { Acetovanillon }\end{array}$} & & & 0.029 \\
\hline & \multicolumn{2}{|c|}{$\begin{array}{l}-0.08 \\
-0.05\end{array}$} & 0.016 \\
\hline & \multicolumn{3}{|c|}{ Exponential } \\
\hline & $\delta$ & $B$ & $\kappa$ \\
\hline Syringol & $1.4 \mathrm{E}-3$ & 0.001 & 0.851 \\
\hline Guaiacol & 0.014 & $2.87 \mathrm{E}-5$ & 1.35 \\
\hline Phenol & $-6.17 \mathrm{E}-4$ & $2.27 \mathrm{E}-6$ & 1.61 \\
\hline Creosol & $1.65 \mathrm{E}-3$ & $1.63 \mathrm{E}-13$ & 3.58 \\
\hline
\end{tabular}

415 The reactions of cellulose, lignin and hemicellulose submitted to HTC were 416 investigated in a broad range of times and temperatures. The main kinetic parameters 417 were determined, and final $\mathrm{pH}$ and hydrochar yield were plotted versus the severity of 418 the process. Hemicellulose and cellulose submitted to HTC produced more acidic 
419 solutions containing higher amounts of FU and 5-HMF, respectively, but the latter 420 compounds did not account for the low $\mathrm{pH}$, which was instead due to low molecular421 weight acids obtained at the same time.

422 The hydrochar yields increased in the order hemicellulose $<$ cellulose $<$ lignin. The 423 hydrochar yields of cellulose and hemicellulose decreased, around $40 \%$, when the 424 severity increased, and lignin was the most stable compound in the most severe 425 conditions. The amount of liquid fraction recovered after HTC of hemicellulose did not 426 change much with severity, whereas that of cellulose was first stable and then dramatically dropped down to $20 \%$. That of lignin slightly decreased when the severity increased.

The kinetics of FU and 5-HMF production were described, using two different models involving consecutive reactions with or without additional side reactions. The pre-exponential factors and activation energies were determined and were comprised within the range of those reported in the open literature. Observed differences were attributed to the broader range of severities used in the present study. Finally, nine phenolic compounds produced by HTC of lignin were also studied, and different behaviours were observed in the range of severities used herein: either a maximum concentration at some optimal severity (vanillin, syringaldehyde and acetosyringone), a continuous linear increase of concentration (guaiacyl acetone and acetovanillone), or a somewhat exponential increase (guaiacol, phenol, syringol and creosol). complex biomass submitted to HTC at various severities. These studies are presently in progress. 
445 The authors gratefully acknowledge the financial support of the CPER 2007-2013

446 "Structuration du Pôle de Compétitivité Fibres Grand'Est” (Competitiveness Fibre 447 Cluster, France), through local (Conseil Général des Vosges), regional (Région 448 Lorraine), national (DRRT and FNADT) and European (FEDER, France) funds. This 449 work was also supported by a grant overseen by the French National Research Agency 450 (ANR) as part of the "Investissements d'Avenir" program (ANR-11-LABX-0002-01, 451 Lab of Excellence ARBRE).

452 
Basso, D., Weiss-Hortala, E., Patuzzi, F., Castello, D., Baratieri, M., Fiori, L., 2015. Hydrothermal carbonization of off-specification compost: A byproduct of the organic municipal solid waste treatment. Bioresour. Technol. 182, 217-224. https://doi.org/10.1016/j.biortech.2015.01.118

Bergius, F., 1915. Zeitschriftfur komprimierte und flussige gase. pp. 17.

Borrero-López, A.M., Fierro, V., Jeder, A., Ouederni, A., Masson, E., Celzard, A., 2017. High added-value products from the hydrothermal carbonisation of olive stones. Environ. Sci. Pollut. Res. 24, 9859-9869. https://doi.org/10.1007/s11356$\underline{016-7807-6}$

Braghiroli, F.L., Fierro, V., Izquierdo, M.T., Parmentier, J., Pizzi, A., Celzard, A., 2012. Nitrogen-doped carbon materials produced from hydrothermally treated tannin. Carbon 50, 5411-5420. https://doi.org/10.1016/j.carbon.2012.07.027

Braghiroli, F.L., Fierro, V., Izquierdo, M.T., Parmentier, J., Pizzi, A., Celzard, A., 2014. Kinetics of the hydrothermal treatment of tannin for producing carbonaceous microspheres. Bioresour. Technol. 151, 271-277. https://doi.org/10.1016/j.biortech.2013.10.045

Braghiroli, F.L., Fierro, V., Parmentier, J., Vidal, L., Gadonneix, P., Celzard, A., 2015. Hydrothermal carbons produced from tannin by modification of the reaction medium: Addition of $\mathrm{H}^{+}$and $\mathrm{Ag}^{+}$. Ind. Crops Prod. 77, 364-374. https://doi.org/10.1016/j.indcrop.2015.09.010

Braghiroli, F.L., Fierro V., Izquierdo M.T., Parmentier J., Pizzi A., Delmotte L., Celzard A., 2015b. High surface — highly N-doped carbons from hydrothermally treated tannin. Ind. Crops Prod. 66, 282-290. https://doi:10.1016/j.indcrop.2014.11.022

Braghiroli, F.L., Fierro, V., Szczurek, A., Gadonneix, P., Ghanbaja, J., Parmentier, J., Medjahdi, G., Celzard, A., 2017. Hydrothermal treatment of tannin: A route to porous metal oxides and metal/carbon hybrid materials. Inorganics 5, 7. https://doi.org/10.3390/inorganics5010007

Chen, L., Huang, H., Liu, W., Peng, N., Huang, X., 2010. Kinetics of the 5hydroxymethylfurfural formation reaction in chinese rice wine. J. Agric. Food Chem. 58, 3507-3511. https://doi.org/10.1021/jf904094q

Chen, X., Tao, L., Shekiro, J., Mohaghaghi, A., Decker, S., Wang, W., Smith, H., Park, S., Himmel, M.E., Tucker, M., 2012. Improved ethanol yield and reduced minimum ethanol selling price (MESP) by modifying low severity dilute acid pretreatment with deacetylation and mechanical refining: 1) Experimental. Biotechnol. Biofuels 5, 1-10. https://doi.org/10.1186/1754-6834-5-60

Chen, Z., Zhang, W., Xu, J., Li, P., 2015. Kinetics of xylose dehydration into furfural in acetic acid. Chinese J. Chem. Eng. 23, 659-666. https://doi.org/10.1016/j.cjche.2013.08.003

Chen, X., Lin, Q., He, R., Zhao, X., Li, G., 2017. Hydrochar production from watermelon peel by hydrothermal carbonization. Bioresour. Technol. 241, 236243. https://doi.org/10.1016/j.biortech.2017.04.012 
Cross, M.M., 1965. Rheology of non-Newtonian fluids: A new flow equation for pseudoplastic systems. J. Colloid
https://doi.org/10.1016/0095-8522(65)90022-X

Danon, B., Hongsiri, W., van der Aa, L., de Jong, W., 2014. Kinetic study on homogeneously catalyzed xylose dehydration to furfural in the presence of arabinose and glucose. Biomass Bioenerg. 66, 364-370. https://doi.org/10.1016/j.biombioe.2014.04.007

Fang, J., Gao, B., Chen, J., Zimmerman, A.R., 2015. Hydrochars derived from plant biomass under various conditions: Characterization and potential applications and impacts. Chem. Eng. J. 267, 253-259. https://doi.org/10.1016/j.cej.2015.01.026

Gao, Y., Wang, X.H., Yang, H.P., Chen, H.P., 2012. Characterization of products from hydrothermal treatments of cellulose. Energy 42, 457-465. https://doi.org/10.1016/j.energy.2012.03.023

Girisuta, B., Janssen, L.P.B.M., Heeres, H.J., 2006. A kinetic study on the decomposition of 5-hydroxymethylfurfural into levulinic acid. Green Chem. 8, 701-709. https://doi.org/10.1039/b518176c

Jatzwauck, M., Schumpe, A., 2015. Kinetics of hydrothermal carbonization (HTC) of soft rush. Biomass Bioenerg. 75, 94-100. https://doi.org/10.1016/j.biombioe.2015.02.006

Jing, Q., Lü, X., 2007. Kinetics of non-catalyzed decomposition of D-xylose in high temperature liquid water. Chin. J. Chem. Eng. 15(5), 666-669. https://doi.org/10.1016/S1004-9541(07)60143-8

Jing, Q., Lü, X., 2008. Kinetics of non-catalyzed decomposition of glucose in hightemperature liquid water. Chin. J. Chem. Eng. 16, 890-894. https://doi.org/10.1016/S1004-9541(09)60012-4

Kang, S., Li, X., Fan, J., Chang, J., 2012. Characterization of hydrochars produced by hydrothermal carbonization of lignin, cellulose, D-xylose, and wood meal. Ind. Eng. Chem. Res. 51, 9023-9031. https://doi.org/10.1021/ie300565d

Kim, S.B., Lee, M.R., Park, E.D., Lee, S.M., Lee, H., Park, K.H., Park, M.J., 2011. Kinetic study of the dehydration of D-xylose in high temperature water. React. Kinet. Mech. Catal. 103, 267-277. https://doi.org/10.1007/s11144-011-0320-5

Ko, J.K., Kim, Y., Ximenes, E., Ladisch, M.R., 2015. Effect of liquid hot water pretreatment severity on properties of hardwood lignin and enzymatic hydrolysis of cellulose. Biotechnol. Bioeng. 112, 252-262. https://doi.org/10.1002/bit.25349

Liu, H., Hu, H., Mojtaba, M., Jahan, M.S., 2014. Kinetics of furfural production from pre-hydrolysis liquor (PHL) of a kraft-based hardwood dissolving pulp production process. Biomass Bioenerg. 66, 320-327. https://doi.org/10.1016/j.biombioe.2014.02.003

Lu, X., Pellechia, P.J., Flora, J.R. V, Berge, N.D., 2013. Influence of reaction time and temperature on product formation and characteristics associated with the hydrothermal carbonization of cellulose. Bioresour. Technol. 138, 180-190. https://doi.org/10.1016/j.biortech.2013.03.163 
Lynam, J.G., Coronella, C.J., Yan, W., Reza, M.T., Vasquez, V.R., 2011. Acetic acid and lithium chloride effects on hydrothermal carbonization of lignocellulosic biomass. Bioresour. Technol. 102, 6192-6199. https://doi.org/10.1016/j.biortech.2011.02.035

Marcotullio, G., Tavares Cardoso, M.A., De Jong, W., Verkooijen, A.H.M., 2009. Bioenergy II: Furfural destruction kinetics during sulphuric acid-catalyzed production from biomass. Int. J. Chem. React. Eng. 7. https://doi.org/10.2202/1542-6580.1980

Marcotullio, G., 2011. The chemistry and technology of furfural production in modern lignocellulose-feedstock biorefineries. Delft University of Technology, Netherlands.

Onwudili, J.A., 2015. Influence of reaction conditions on the composition of liquid products from two-stage catalytic hydrothermal processing of lignin. Bioresour. Technol. 187, 60-69. https://doi.org/10.1016/j.biortech.2015.03.088

Overend, R.P., Chornet, E., 1987. Fractionation of lignocellulosics by steam-aqueous pretreatments. Philos. Trans. R. Soc. Lond. 321, 523-536. https://doi.org/10.1098/rsta.1987.0029

Perez, R.F., Fraga, M.A., 2014. Hemicellulose-derived chemicals: One-step production of furfuryl alcohol from xylose. Green Chem. 16, 3942-3950. https://doi.org/10.1039/c4gc00398e

Pińkowska, H., Wolak, P., Złocińska, A., 2011. Hydrothermal decomposition of xylan as a model substance for plant biomass waste - Hydrothermolysis in subcritical water. Biomass Bioenerg. 35, 3902-3912. https://doi.org/10.1016/j.biombioe.2011.06.015

Rasmussen, H., Sørensen, H.R., Meyer, A.S., 2014. Formation of degradation compounds from lignocellulosic biomass in the biorefinery: Sugar reaction mechanisms. Carbohydr. $\quad$ Res. 385, 45-57. https://doi.org/10.1016/j.carres.2013.08.029

Reza, M.T., Becker, W., Sachsenheimer, K., Mumme, J., 2014. Hydrothermal carbonization (HTC): Near infrared spectroscopy and partial least-squares regression for determination of selective components in HTC solid and liquid products derived from maize silage. Bioresour. Technol. 161, 91-101. https://doi.org/10.1016/j.biortech.2014.03.008

Reza, M.T., Rottler, E., Herklotz, L., Wirth, B., 2015. Hydrothermal carbonization (HTC) of wheat straw: Influence of feedwater $\mathrm{pH}$ prepared by acetic acid and potassium hydroxide. Bioresour. Technol. 182, 336-344. https://doi.org/10.1016/j.biortech.2015.02.024

Selmi, T., Sanchez-Sanchez, A., Gadonneix, P., Jagiello, J., Seffen, M., Sammouda, H., Celzard, A., Fierro, V., 2018. Tetracycline removal with activated carbons produced by hydrothermal carbonisation of Agave americana fibres and mimosa tannin. Ind. Crops Prod. 115, 146-157. https://doi.org/10.1016/j.indcrop.2018.02.005

Shen, J. Wyman, C.E., 2012. Hydrochloric acid-catalyzed levulinic acid formation from cellulose: Data and kinetic model to maximize yields. AIChE J. 58 (1), 236-246. https://doi.org/10.1002/aic.12556 
Steinbeiss, S., Gleixner, G., Antonietti, M., 2009. Effect of biochar amendment on soil carbon balance and soil microbial activity. Soil Biol. Biochem. 41, 1301-1310. https://doi.org/10.1016/j.soilbio.2009.03.016

Wang, Y., Yang, R., Li, M., Zhao, Z., 2015. Hydrothermal preparation of highly porous carbon spheres from hemp (Cannabis sativa L.) stem hemicellulose for use in energy-related applications. Ind. Crops Prod. 65, 216-226. https://doi.org/10.1016/j.indcrop.2014.12.008

Xu, J., Chen, Y., Cheng, J.J., Sharma-Shivappa, R.R., Burns, J.C., 2011. Delignification of switchgrass cultivars for bioethanol production. BioResources 6, 707-720. https://doi.org/10.15376/biores.6.1.707-720

Yang, G., Pidko, E.A., Hensen, E.J.M., 2012. Mechanism of Bronsted acid-catalyzed conversion of carbohydrates. J. Catal. 295, 122-132. https://doi.org/10.1016/j.jcat.2012.08.002

Yemiş. O., Mazza, G., 2012. Optimization of furfural and 5-hydroxymethylfurfural production from wheat straw by a microwave-assisted process. Bioresour. Technol. 109, 215-223. https://doi.org/10.1016/j.biortech.2012.01.031

Zeitsch, K.J., 2000. The chemistry and technology of furfural and its many by-products, volume 13, first ed. Elsevier, Amsterdam.

Zhou, X.F., 2014. Conversion of kraft lignin under hydrothermal conditions. Bioresour. Technol. 170, 583-586. https://doi.org/10.1016/j.biortech.2014.08.076 